\title{
El Castellet de Banyoles (Tivissa): Una ciudad ibérica en el curso inferior del río Ebro
}

\section{Castellet de Banyoles (Tivissa): An Iberian city on the lower Ebro valley}

\author{
Joan Sanmartí \\ Universidad de Barcelona e Institut d'Estudis Catalans \\ David Asensio \\ Universidad de Barcelona e Institut d'Estudis Catalans \\ M. ${ }^{\text {a }}$ Teresa Miró \\ Generalitat de Catalunya, Serveis Territorials a Tarragona \\ Rafael Jornet \\ MÓN IBER ROCS S.L. Recerca i difusió de la Cultura Ibèrica
}

\section{RESUMEN}

Aunque es un yacimiento recurrentemente mencionado en la bibliografía especializada, hasta hace pocos años el Castellet de Banyoles sólo era realmente conocido por los hallazgos monetarios y de elementos suntuarios de carácter ritual, a parte de las torres pentagonales de tipo helenístico que flanquean su puerta. Los trabajos realizados desde 1998 han permitido precisar la datación del primer asentamiento entre el último tercio del siglo III a.C. y principios del II a.C., y han mostrado la existencia en ese momento de una muralla de compartimentos de tipo púnico. También han traído a luz un extenso sector de hábitat —que probablemente corresponde a un grupo gentilicio-, con casas de distintos tipos y tamaños, y un posible santuario. Con una superficie de 4,5 ha, se trata de una pequeña ciudad que agrupaba toda la población de la hoya de Móra, siguiendo un modelo mononuclear inédito en el mundo ibérico septentrional, y que tal vez se explique por razones estratégicas en un contexto histórico convulso a causa de la expansión bárquida y la segunda guerra púnica.

\section{SUMMARY}

While recurrently cited in the specialized bibliography, until recent years Castellet de Banyoles was only really known by the findings of monetary hoards and some luxury ritual vases, in addition to the Hellenistic-type pentagonal towers flanking the site entrance. Excavation work since 1998 has enabled precise dating of the first settlement between the last third of the $3^{\text {rd }}$ century BC and early $2^{\text {nd }}$ century BC, and has revealed the existence at that time of a Punic-type compartments wall, as well as an extensive dwelling area, which probably corresponds to a specific gens. Houses of different types and sizes are attested, as well as a possible sanctuary. With an area of 4.5 ha, Castellet de Banyoles is a small city that brought together the entire population of the Mora basin, following a mononuclear model unprecedented in the northern
Iberian world. This is likely explained by strategic reasons in a turbulent historical context due to the Barcid expansion in the Iberian Peninsula and the Second Punic War.

PALABRAS CLAVES: Cultura ibérica, urbanismo, arquitectura doméstica, arquitectura militar, estructura social, religión.

KEY WORDS: Iberian culture, urbanism, domestic architecture, military architecture, social structure, religion.

\section{SITUACIÓN}

El asentamiento ibérico del Castellet de Banyoles está situado en el término municipal de Tivissa (Ribera d'Ebre, Tarragona), a unos $7 \mathrm{~km}$ de esta población, en el centro aproximadamente de la cubeta de Mora, una amplia hoya de casi 7000 ha de superficie y de considerable potencial agrícola (Fig. 1).

El asentamiento se sitúa sobre una plataforma cuaternaria prácticamente llana, de unas 4,5 ha de superficie, recortada en la primera terraza fluvial del margen izquierdo del Ebro por los torrentes que desaguan en este río, cuyo curso se encuentra actualmente al pie del límite occidental de aquélla (Fig. 2).

Sus coordenadas geográficas, tomadas aproximadamente en el centro del yacimiento, son $41^{\circ} 03^{\prime} 42.17$ $\mathrm{N}$ y 0³9'65.23" E, y su altitud s.n.m., en el mismo punto, de $127 \mathrm{~m}$. 


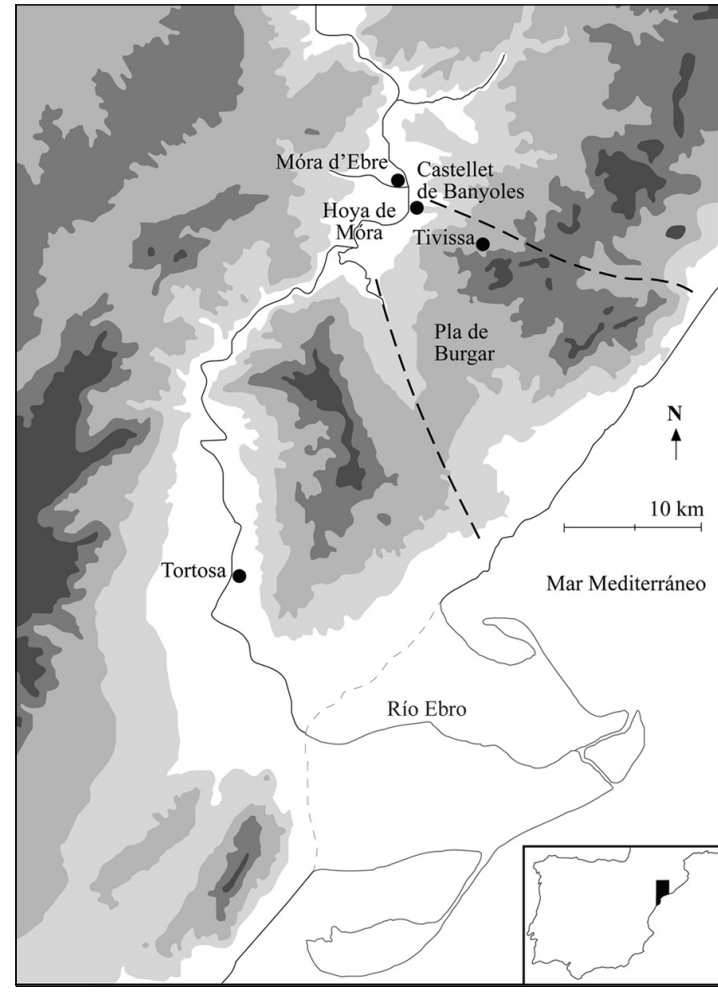

Figura 1. Mapa de situación del Castellet de Banyoles, con indicación de las principales vías de comunicación con la costa.
La plataforma en que se encuentra el yacimiento tiene aproximadamente la forma de un triángulo isósceles, con el lado desigual al oeste, más o menos paralelo al curso del Ebro, y queda netamente delimitada por pendientes extremadamente abruptas, casi verticales, de hecho, al sur $\mathrm{y}$, sobre todo, al oeste. $\mathrm{Su}$ aspecto general es, pues, el de una península, con un largo istmo de $120 \mathrm{~m}$ de longitud por tan sólo $8 \mathrm{~m}$ de anchura, situado al este. Dado que su altitud relativa es de unos $100 \mathrm{~m}$, el lugar presenta unas condiciones defensivas excelentes, ya que solamente es accesible con relativa comodidad por el estrecho paso situado al este, de fácil defensa. A pesar de su altitud relativamente reducida, el Castellet de Banyoles ejerce un dominio visual sobre la casi totalidad de la hoya de Mora y, por supuesto, sobre el tránsito fluvial a través del Ebro (Fig. 3).

Además controla, de forma casi inmediata, la vía terrestre que une la cubeta con la costa por Tivissa y el valle del Llastres, y también, algo más al sur, el camino que conduce a las bocas del Ebro por el Pla de Burgar y El Perelló (Noguera 2002: 15-18). En definitiva, por su situación y por sus características topográficas, se trata de un emplazamiento privilegiado desde el punto de vista defensivo y del control del territorio, mientras que su amplia superficie llana le hace particularmente apropiado para establecer un asentamiento de grandes dimensiones.

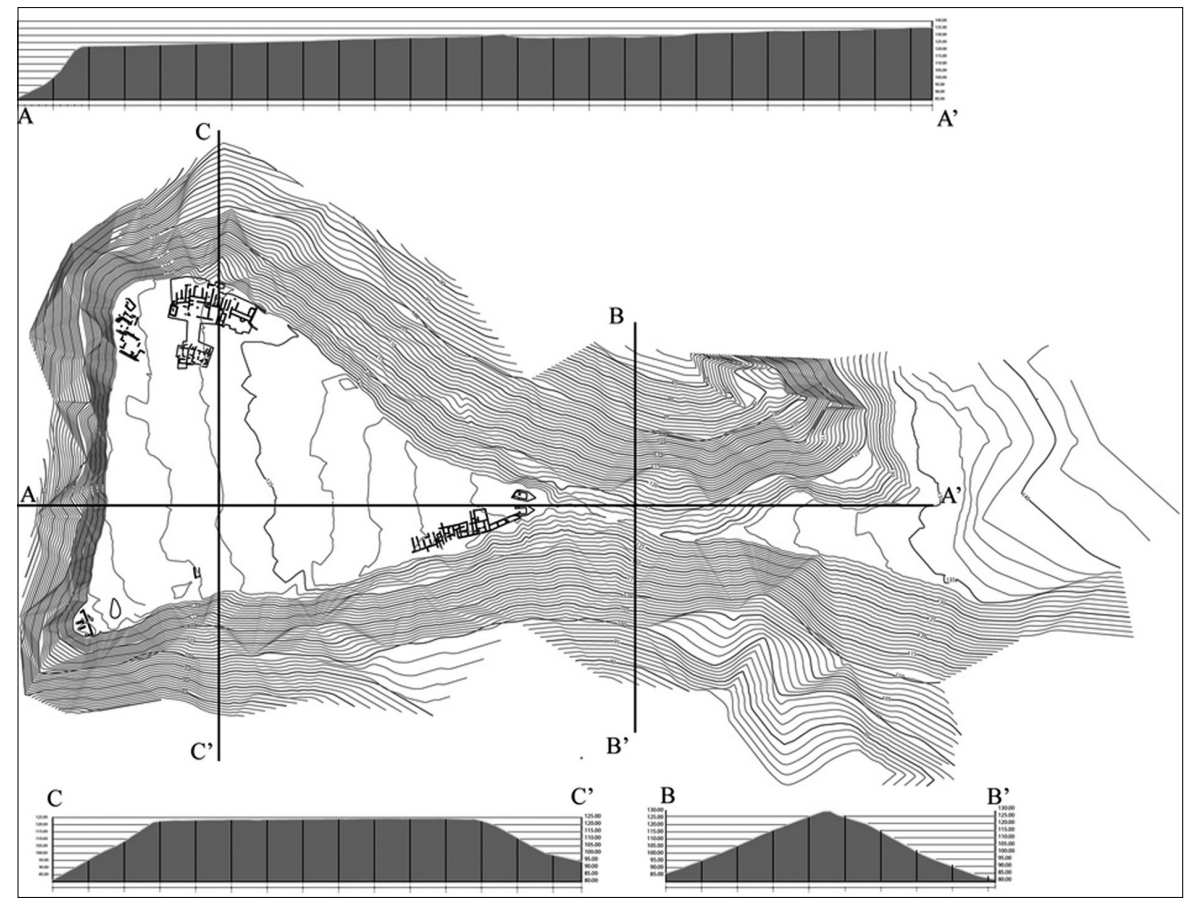

Figura 2. Topografía del Castellet de Banyoles. 


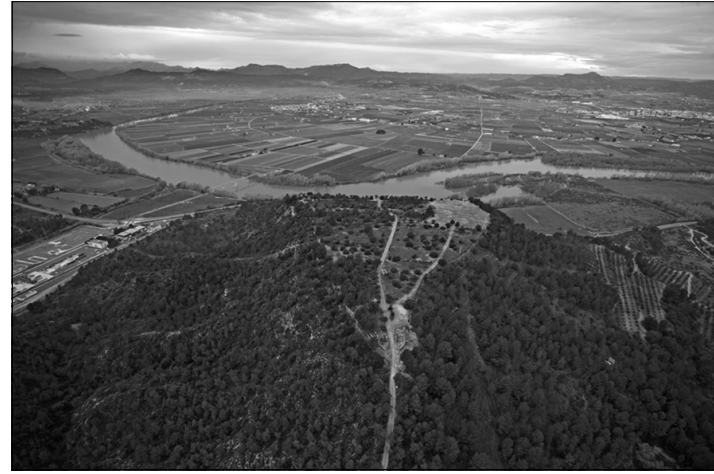

Figura 3. Vista del Castellet de Banyoles y la hoya de Móra desde el este.

\section{ANTECEDENTES DE LA INVESTIGACIÓN}

Desde que aparecieran las primeras noticias sobre el mismo (Bosch Gimpera 1915), el Castellet de Banyoles ha sido uno de los yacimientos ibéricos más citados en la bibliografía sobre el mundo ibérico. $\mathrm{Su}$ fama obedece sobre todo a los distintos hallazgos de joyas, monedas y vasos argénteos efectuados durante el primer tercio del siglo xx (Serra Ràfols 1941:
15-16); estos últimos, en particular, han dado pie a una extensa literatura, relacionada sobre todo con la interpretación de las representaciones que aparecen en las cuatro phiálai mesómphaloi halladas en 1927 (Serra Ràfols 1941: 25-32; García y Bellido 1950; Fernández Fuster 1955; Blázquez 1955-56 y $1957-$ 58; Marín Ceballos 1983; Pallarès 1987; Olmos 1996), un aspecto sobre el que no entraremos directamente en este trabajo.

Por el contrario, el conocimiento sobre la estructura urbanística y la arquitectura del asentamiento -y, por tanto, las posibilidades de interpretación sobre la naturaleza del mismo- ha quedado reducido hasta fechas recientes a un sector, relativamente pequeño, de su extremo oriental (Figs. 4 y 5). Este incluye, por una parte, el acceso al poblado, que estaba protegido por las famosas torres pentagonales traídas a luz en las campañas de 1932 (dirigida por J. Brull) y 1937 (conducida por él mismo y J. de C. Serra Ràfols); por otra, un sector de habitación relativamente extenso (unos $500 \mathrm{~m}^{2}$ ), situado al sudoeste de las torres. Este último fue descubierto por los mismos Brull y Serra Ràfols, además de S. Vilaseca, en 1942 y 1943, y publicado unos años más tarde (Vilaseca et alii 1949). Excavado con la metodo-

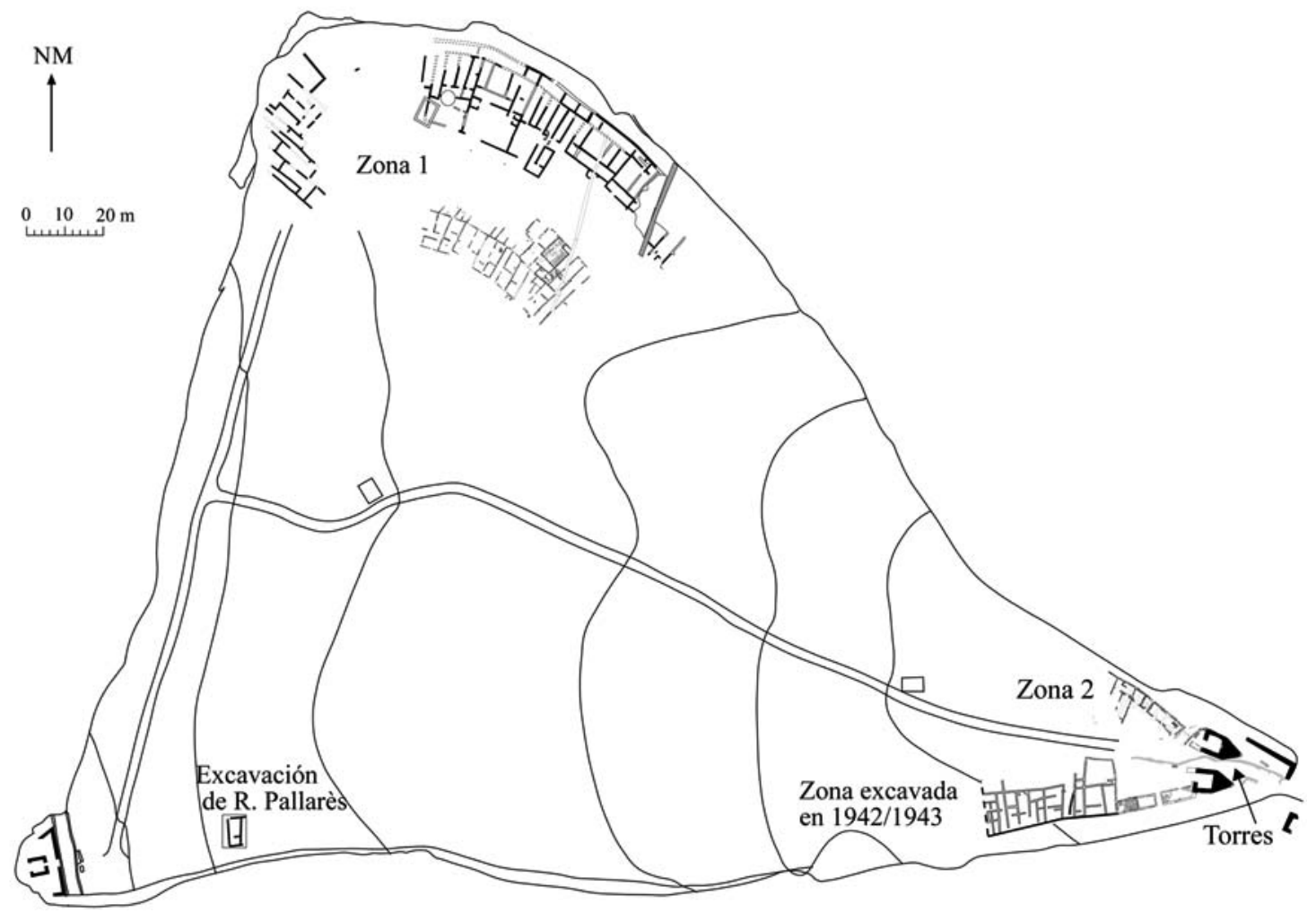

Figura 4. Esquema topográfico del Castellet de Banyoles con indicación de las zonas excavadas. 


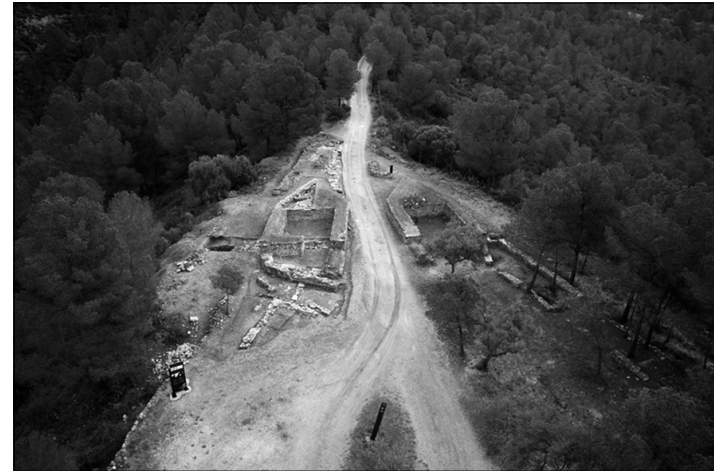

Figura 5. Vista de las torres pentagonales desde el oeste.

logía al uso en los años cuarenta, la naturaleza de este sector no resulta claramente comprensible, ni en la publicación, ni, en la actualidad, a partir de los restos conservados, que constituyen un conjunto confuso de muros en el que resulta complicado reconocer estructuras bien definidas. A partir de 1944, la investigación en el yacimiento quedó interrumpida durante largos años, hasta que la Universidad de Barcelona, a través de Ramon Pallarès, reemprendió las excavaciones, a finales de los años setenta. Estos trabajos se limitaron, sin embargo, a la realización de catas relativamente pequeñas en la zona de acceso y en el extremo opuesto del poblado (Pallarès, 1984a, 1984b y 1987), por lo que apenas contribuyeron a la comprensión de su estructura.

\section{EL PROYECTO DE LA UNIVERSIDAD DE BARCELONA Y EL MUSEU NACIONAL D'ARQUEOLOGIA DE CATALUNYA}

En el umbral del siglo xxI, el conocimiento real sobre el Castellet de Banyoles era muy reducido, a pesar de la fama del yacimiento. Incluso las piezas de mayor renombre, como las phiálai mesómphaloi, no dejaban de ser elementos descontextualizados, que solamente podían ser interpretados por sí mismos. En 1998, la Universidad de Barcelona y el Museu d'Arqueologia de Catalunya iniciaron una nueva etapa de estudio del yacimiento, en el marco del proyecto de investigación "Les estratègies d'ocupació del territori i la seva evolució a l'àrea del curs inferior de l'Ebre durant la Protohistòria i l'antiguitat", patrocinado por el Servei d'Arqueologia de la Generalitat de Catalunya y dirigido por uno de nosotros (J. S.). En los años precedentes, este proyecto se había orientado fundamentalmente al estudio del Bronce

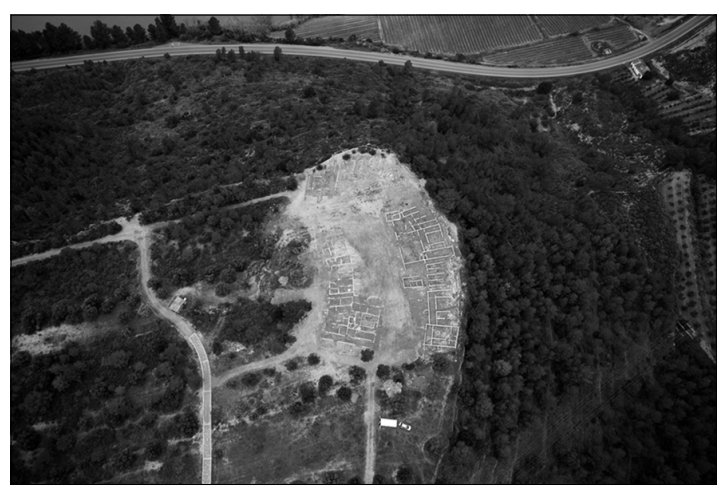

Figura 6. El ángulo noroeste del Castellet de Banyoles y la zona 1.

Final y la Primera Edad del Hierro de la zona (Asensio et alii 1994-1996a y 1994-1996b; Sanmartí et alii 2000). La intervención en el Castellet de Banyoles era la continuación lógica de estos trabajos.

Las campañas de excavación y consolidación realizadas desde 1998 han afectado, en primer lugar, a una amplia zona (unos $6000 \mathrm{~m}^{2}$ ) de la parte noroccidental del yacimiento (zona 1), donde se ha traído a luz parte de la muralla, diversas calles, casas de variadas formas y tipos, y un interesante edificio que creemos relacionado con actividades cultuales (Figs. 4 y 6$)$.

En los últimos años, nuestra actividad se ha desplazado al área de la puerta flanqueada por las célebres torres pentagonales (zona 2), con objeto de precisar su cronología (Figs. 4 y 7).

Después de trece años de trabajos, cuyos resultados se han publicado de forma parcial y dispersa (Asensio et alii 2002 y 2005), creemos llegado el momento de ofrecer una visión de conjunto, que reúna en una interpretación coherente el importante volumen de datos que se han recuperado, que anali-

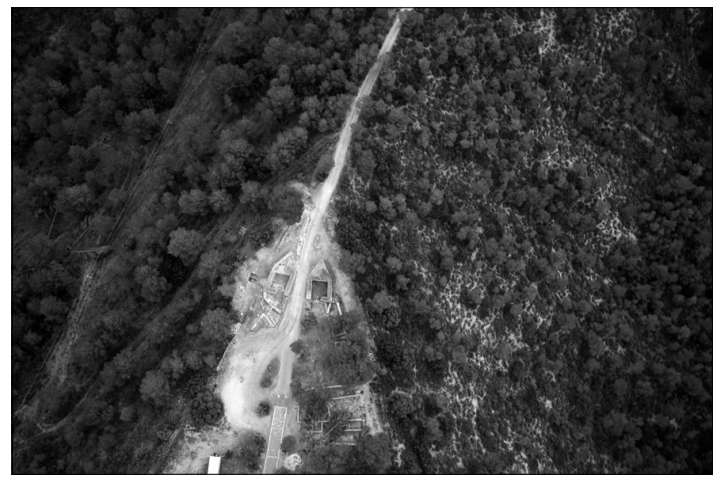

Figura 7. Vista cenital de la puerta del Castellet de Banyoles. 
ce también las aportaciones recientes de Pierre Moret sobre la cronología y filiación de las torres pentagonales (Moret 2008) y, por último, que evalúe la significación histórica de este importante asentamiento en su contexto regional.

\section{URBANISMO Y ARQUITECTURA DEL CASTELLET DE BANYOLES}

\subsection{LA ESTRUCTURA URBANÍSTICA}

Como ya se ha dicho, la estructura urbanística del asentamiento era apenas conocida antes de nuestra intervención. Se suponía, en general, que estaba protegido por un muro perimetral — cuya naturaleza era discutida ${ }^{1}$ - , y que el conjunto urbano se articulaba a partir de una calle axial, orientada en dirección esteoeste, que, partiendo de la puerta protegida por las torres, debía de alcanzar el extremo opuesto de la plataforma. De la naturaleza de las construcciones, casi nada se sabía, exceptuando el sector excavado en los años cuarenta y las catas practicadas por Ramon Pallarès.

Nuestro proyecto ha permitido demostrar la existencia de una muralla de compartimentos — que será descrita más adelante-, directamente relacionada con las torres pentagonales que protegen la entrada y que seguía estrechamente el límite de la plataforma en que se estableció el poblado, incluso aparentemente en el lado occidental, ${ }^{2}$ donde las condiciones topográficas permitirían prescindir de ella. Esta muralla es el elemento primero del trazado urbano, el que se elevó en primer lugar (aunque en muchos casos debió de hacerse a la vez que las casas que se le adosan) y el que rige la organización global del asentamiento.

En cuanto al trazado viario, comienza ahora a ser conocido, sobre todo a partir de los trabajos realizados en la zona noroeste (Fig. 8).

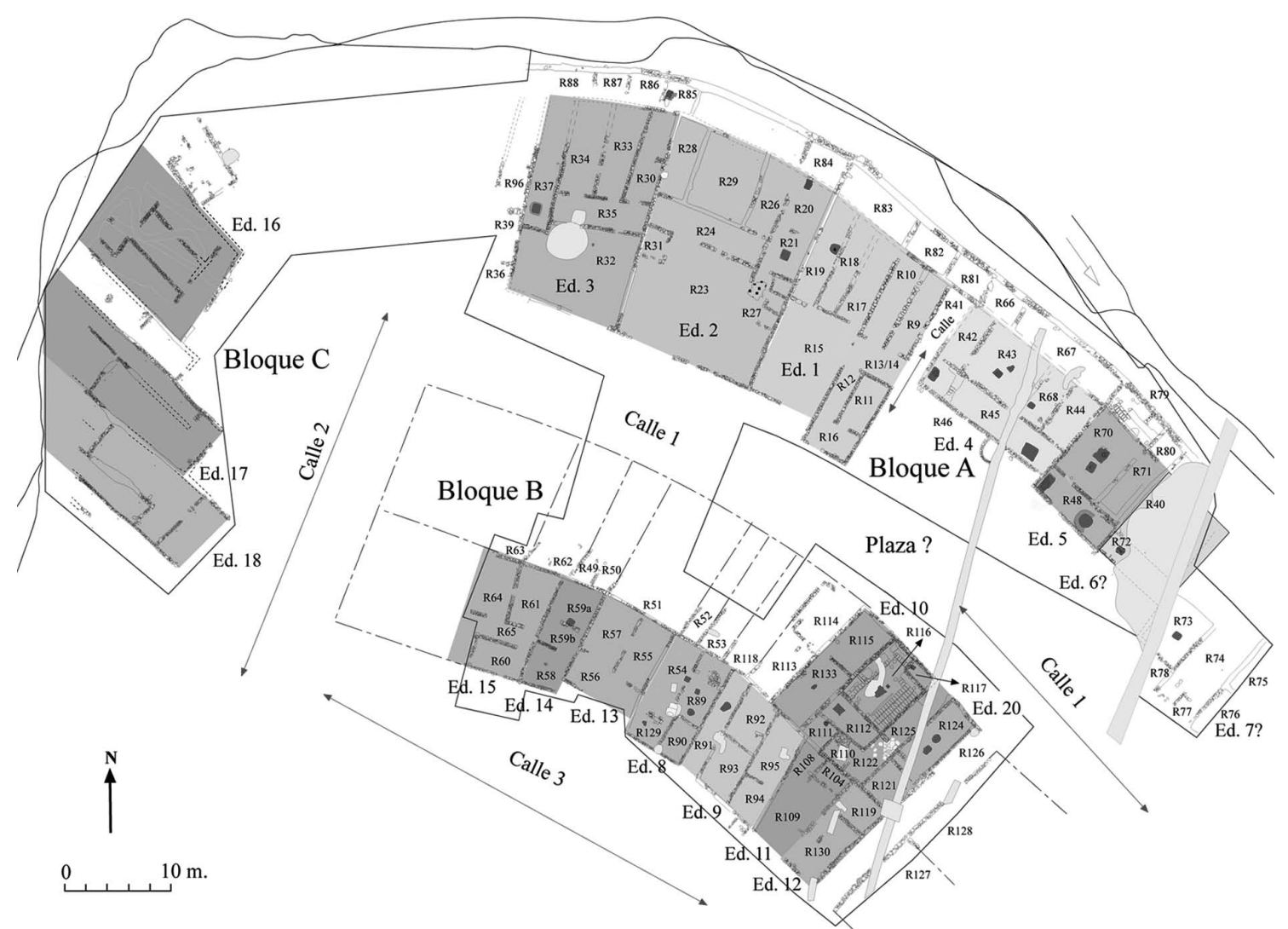

Figura 8. Planta de la zona 1.

${ }^{1}$ Véase el apartado dedicado al sistema defensivo.

${ }^{2}$ Según se deduce de los trabajos realizados en 2011, aunque este extremo deberá precisarse en el futuro. 


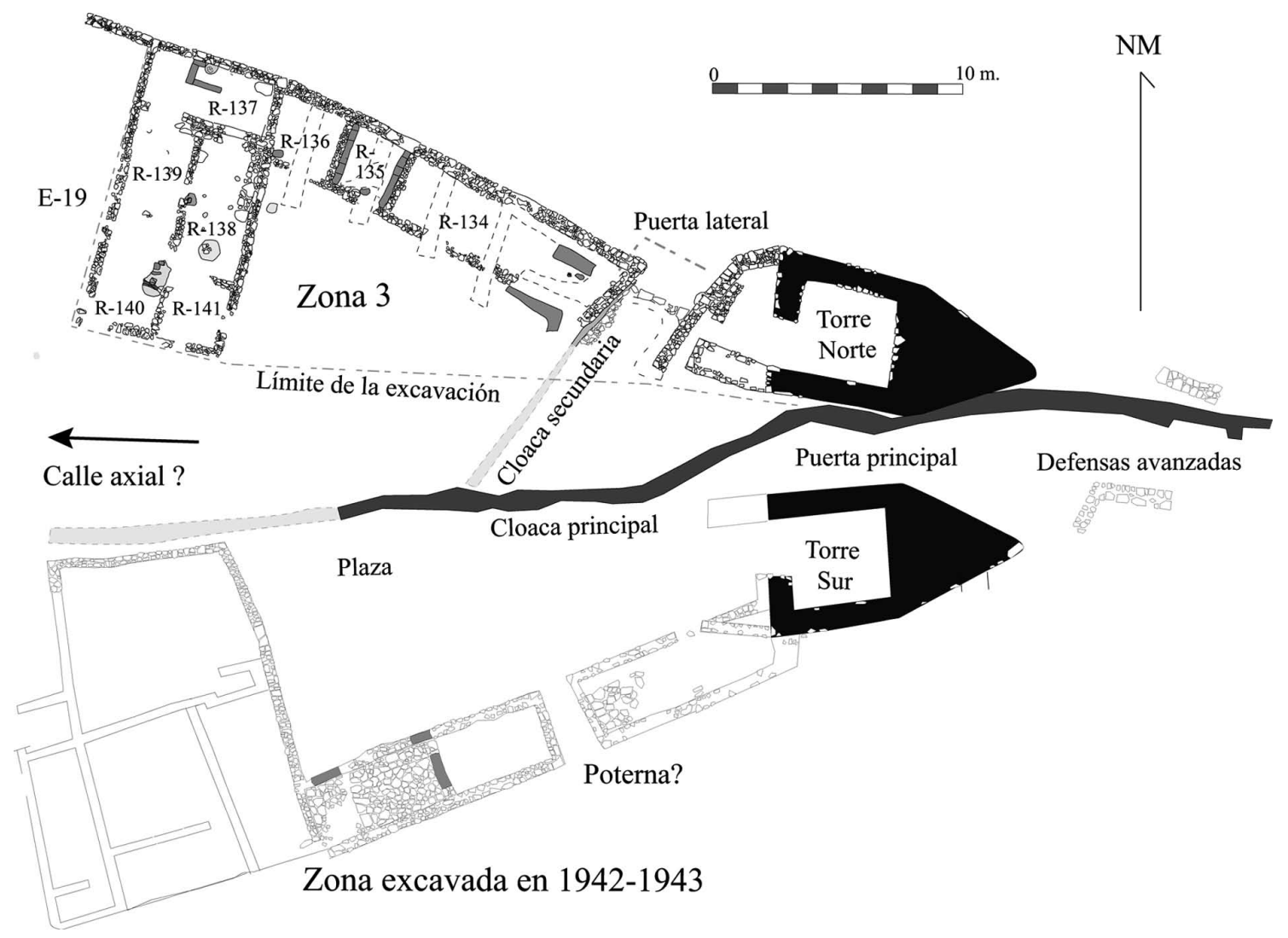

Figura 9. Planta de la zona 2.

Desafortunadamente, el estado de conservación de esta parte del poblado es, a menudo, deficiente; muchos muros han sido destruidos por la secular actividad agrícola o han sido expoliados para obtener material destinado a la erección de terrazas y paredes de delimitación de partidas; a ello debe añadirse la presencia militar y la excavación de trincheras en el año 1938 —en ocasión de la batalla del Ebro-, el arranque de arbolado, las excavaciones clandestinas, etc. Con todo, los restos preservados -o, en su caso, las trincheras de expolio- permiten restituir una trama urbana regular, con amplias calles cuyo trazado sigue el perfil curvilíneo que tiene, en esta zona, la plataforma en que se ubica el asentamiento. Es posible distinguir tres bloques constructivos (A, B, C), separados por vías de circulación, una de las cuales (calle 1), entre los bloques A y B y orientada en dirección noroeste-sudeste, medía unos $10 \mathrm{~m}$ de ancho. Al sur-sudeste del bloque B, debió de existir una segunda vía (calle 3), de trazado paralelo a la calle 1 y cuya anchura es todavía desconocida. En cuanto a las calles transversales, orientadas en dirección nordeste a sudoeste, se han identificado dos callejas de poco más de $2 \mathrm{~m}$ de ancho, situadas respectivamente entre los edificios 1 y 4 (R41) y en el límite sudoccidental del bloque constructivo $\mathrm{B}$ (R126). ${ }^{3} \mathrm{Al}$ noroeste, el espacio de circulación entre el bloque $\mathrm{C}$ y los bloques A y B no ha sido suficientemente investigado y sigue aún mal definido. Los restos conocidos sugieren, sin embargo, la existencia de una ancha calle, tal vez incluso de una plaza (calle 2). Es importante observar que, en la parte sudoriental de la zona excavada, la calle 1 se ensancha extraordinariamente, hasta formar una plaza de unos $20 \mathrm{~m}$ de anchura, situada entre los edificios 45 , al norte, y el edificio 10 , al sur.

El resto de la red viaria es desconocido, aunque puede suponerse que seguía unas pautas similares, es decir, con grandes calles en dirección noroeste-sudeste y este-oeste, y vías transversales de entidad mu-

\footnotetext{
${ }^{3}$ Existe otra calle transversal, de 3,30 $\mathrm{m}$ de anchura en el sector excavado en 1942-1943, pero podría corresponder a la última etapa de ocupación, fechada a partir de mediados del siglo II a.C. (Vilaseca et alii 1949: 19).
} 
cho menor. ${ }^{4}$ La existencia de una gran calle axial en la que desembocarían las vías más importantes no ha podido ser comprobada, pero nos parece muy probable. Su extremo oriental se reconocería actualmente en la zona 3, en proximidad de la entrada (Fig. 9).

Aquí, los trabajos de excavación han mostrado que la puerta del asentamiento daba paso a un gran espacio abierto, delimitado por los dos extremos orientales de la muralla y, al oeste, por dos edificios que se proyectan hacia el norte y hacia el sur respectivamente, dejando entre ellos un paso de unos $12 \mathrm{~m}$., que constituye el inicio de la que debió de ser la calle principal.

\section{ALGUNAS CUESTIONES DE ESTRATIGRAFÍA Y CRONOLOGÍA}

La estratigrafía documentada es siempre extremadamente simple, y también extremadamente homogénea. Efectivamente, en todos los recintos excavados se comprueba la existencia de un estrato de abandono - a menudo sin duda de destrucción-, cuya potencia máxima conservada nunca rebasa los $0,30 \mathrm{~m}$, lo que sin duda se debe a la intensa acción antrópica posterior al abandono del lugar. Estas capas de derrumbe contienen a menudo una notable cantidad de cenizas, vasos cerámicos fragmentados in situ y restos de adobes y revestimientos de muros; también, en algún caso, objetos de gran valor, concretamente monedas de plata y joyas de oro (Fig. 10), y probablemente una lámina de plomo inscrita (Asensio et alii 2003).

Por consiguiente, puede hablarse de un nivel de abandono generalizado, tanto en las zonas excavadas por nosotros como en la que fue descubierta en los años cuarenta (Vilaseca et alii 1949: 16, 46). La violencia del episodio que puso fin al asentamiento viene también avalada por el hallazgo de abundantes "proyectiles de piedra (cantos rodados esféricos y piedras redondeadas artificialmente), glandes de plomo y puntas de flecha de hierro" en la zona de la puerta (Vilaseca et alii 1949: 16) y, en el sector noroeste, excavado por nosotros, de otros glandes de plomo procedentes del nivel superficial.

La datación de este nivel de destrucción constituye un aspecto esencial para la correcta interpretación del yacimiento, de modo que vale la pena dedicarle un cierto espacio. En trabajos anteriores le

\footnotetext{
${ }^{4}$ Lamentablemente, la mala conservación de las estructuras hace muy difícil la aplicación de los métodos de prospección geofísica.
}

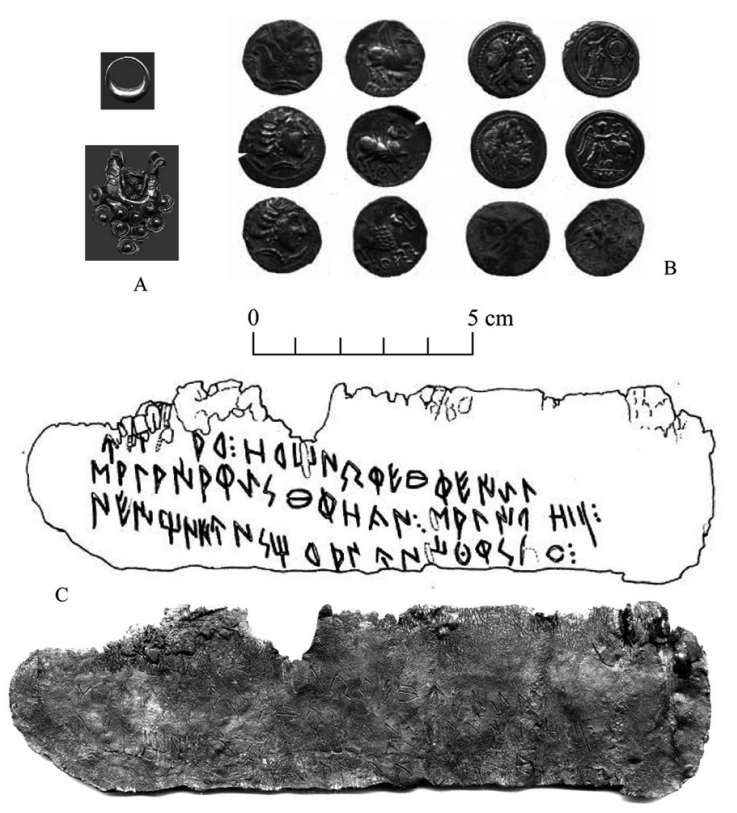

Figura 10. a) Joyas de oro; b) monedas de plata; c) lámina de plomo con inscripción ibérica.

atribuimos una cronología comprendida entre los últimos años del siglo III a.C. y los primeros de la siguiente centuria, lo que nos llevó a pensar que su formación pudo ser consecuencia, bien de la represión de la sublevación de Indíbil y Mandonio, en 206205 a.C., bien de la campaña de Catón en 195 a.C. (Asensio et alii 2002: 200; Asensio et alii 2005: 620). Esta cronología había sido ya propuesta por Bosch Gimpera en 1915, a partir del análisis por A. Vives Escudero de las primeras monedas descubiertas en el yacimiento (Bosch 1915: 858), y ha sido posteriormente mantenida, con distintos matices, por otros autores. Así, Serra Ràfols intentó relacionar el fin del asentamiento con los primeros episodios del enfrentamiento entre romanos y cartagineses, en 218 a.C. (Vilaseca et alii 1949: 53; Serra Ràfols 1965). Mucho más tarde, y a partir del estudio de los materiales recuperados en las campañas de 1942-1943, David Asensio, Xabier Cela y Conxita Ferrer propusieron una fecha algo más baja, en torno a 200 a.C. (Asensio et alii 1996), que creemos corroborada por nuestros hallazgos.

Nuestra apreciación sobre la cronología se basa esencialmente en la datación, establecida por Núria Tarradell-Font, de las monedas de plata halladas en nuestras excavaciones (más concretamente en los recintos 15 y 19, del edificio 1) y de las procedentes de hallazgos anteriores, pero que, siendo a menudo de los mismos tipos, pueden ser relacionadas 
con las primeras, lo que lleva a suponer que proceden del mismo nivel de destrucción, o tal vez de depósitos intencionales relacionados con los mismos acontecimientos que la provocaron ${ }^{5}$. Estas monedas corresponden, por una parte, a emisiones peninsulares de cronología relativamente imprecisa (dracmas de Ampurias, imitaciones ibéricas de éstas y dracmas de Arse) y, por otra, a monedas romanas (cuadrigatos, victoriatos y, sobre todo, denarios) fechables entre 211 a.C. (o 215 a.C.) y 208 a.C. (Fig. 10 B). El hecho de que hayan circulado, según muestra su desgaste, indica que su amortización se produjo algún tiempo después de su acuñación, por lo que N. Tarradell propuso la campaña de Catón —es decir, el año 195 a.C. - como causa más verosímil de la destrucción del asentamiento. Es importante señalar que, después de trece campañas de excavación, no hemos hallado en el mencionado nivel de abandono ni una sola moneda de cronología posterior a la indicada, de modo que difícilmente pudo formarse este estrato mucho después de los años en torno a 200 a.C. ${ }^{6} \mathrm{La}$ fecha de 195 a.C. parece, pues, perfectamente lógica - aunque evidentemente no incuestionable- , a tenor de lo conocido sobre los acontecimientos militares de la época. Pese a ello, en un artículo reciente Pierre Moret ha creído preferible atribuir la destrucción del yacimiento a otros hispani, en un momento algo más avanzado de la primera mitad del siglo II a.C. (Moret 2008: 213).

Aparte del material numismático, nuestra datación se apoya en las cerámicas de importación, en particular la campaniense A y las ánforas grecoitálicas. Por lo que respecta a la primera, el repertorio documentado es característico de la fase antigua de esta producción, es decir, la comprendida entre 220 a.C. y 180 a.C. aproximadamente, según muestra la presencia de las formas Lamb. 23, Lamb. 27ab, Lamb. 28ab, Lamb. 33a, Lamb. 34, Lamb. 36, Morel 68 y diversos fragmentos de base atribuibles sea a esta forma - atestiguada también por fragmentos de asa-, sea a las formas Lamb. 48A o Lamb. 49B (Fig. 11, n 13-20; Fig. 12, no 1-7 y 15-16).

Es cierto que todas y cada una de estas formas excepto el plato de pescado forma Lamb. 23- po-

\footnotetext{
${ }^{5}$ Se hallará un análisis exhaustivo del material numismático hallado en el Castellet de Banyoles, así como una discusión detallada sobre la cronología, en Tarradell-Font 2003 2004.

${ }^{6}$ Aun tratándose de un argumento ex silentio, es preciso reconocer que, en caso de haber continuado existiendo un asentamiento de la entidad del Castellet de Banyoles durante la primera mitad del siglo II a.C., sería sorprendente que no hubiera proporcionado ninguna moneda de este momento, ni en estratigrafía ni en superficie.
}

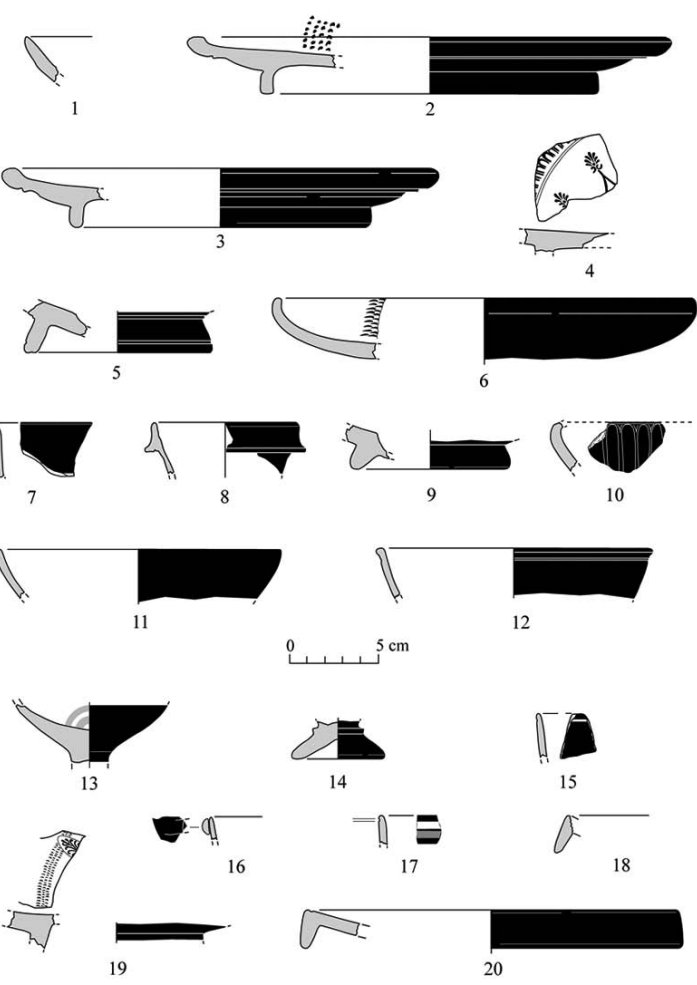

Figura 11. Cerámica importada de los niveles de abandono de la Zona 1: 1 a 6) Ática de barniz negro; 7) Taller de las pequeñas estampillas; 8 a 12) Taller de Roses; 13 a 20) Campaniense $\mathrm{A}$.

drían fecharse en la fase media (180 a.C.-100 a.C.), y también lo es que el uso de todos estos vasos podría haber perdurado durante largos decenios. Ahora bien, no puede olvidarse que faltan las formas características de la mencionada fase media, incluyendo los platos Lamb. 5, que se documentan desde el segundo cuarto del siglo II a.C. (Sanmartí-Grego y Principal 1998: 208), o tal vez incluso algo antes, a juzgar por los hallazgos de Lattara (Adroher 1998: 235). En cuanto a las ánforas greco-itálicas, los cuatro fragmentos de borde recuperados (Fig. 12, n ${ }^{\circ}$ 10-14) pueden corresponder a la facies de campaniense A que hemos descrito. Aunque menos precisa, como es lógico, que la datación de base numismática, la cronología de las importaciones cerámicas es perfectamente coherente con una datación muy a "principios" del siglo II a.C.

Más difícil de precisar es la fecha inicial del sistema urbanístico reconocido hasta el momento. Bajo los niveles de destrucción aparecen finos pavimentos, depositados a su vez sobre las gravas naturales. Estos pavimentos contienen escasos materiales, casi siempre desprovistos de significación cronológica. 


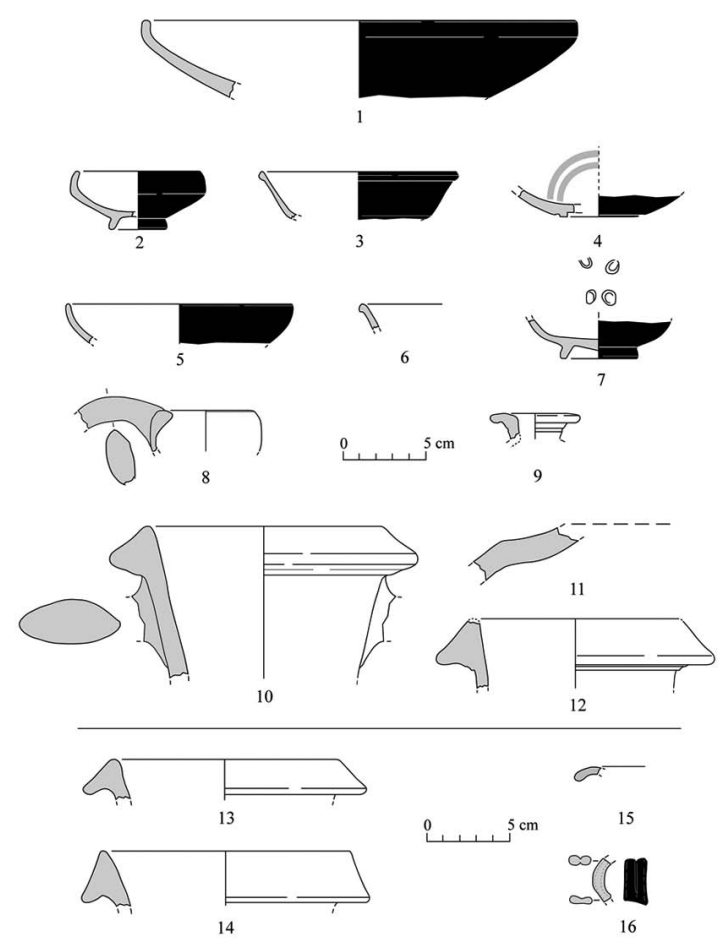

Figura 12. Cerámica importada de los niveles de abandono de la Zona 1: 1 a 7) Campaniense A; 8) Cerámica púnica centro-mediterránea; 9) Cerámica común itálica; 10 a 12) Ánforas greco-itálicas. Cerámica importada de los niveles de abandono de la Zona 2: 13 y 14) Ánforas greco-itálicas; 15 y 16) Campaniense A.

Por otra parte, apenas se han observado reformas constructivas y, cuando existen, son de escasa entidad. Todo ello sugiere una fecha de fundación no muy alejada de la de destrucción: tal vez una o dos generaciones antes, es decir, a mediados del siglo III a.C. como muy pronto.

Es necesario señalar, con todo, que entre los materiales de los niveles de abandono aparece siempre una pequeña cantidad de cerámicas más antiguas. Se trata, en primer lugar, de vasos áticos de barniz negro (Fig. 11, no 1-6), en su mayoría de siglo iv a.C. avanzado, aunque alguno remonta a la segunda mitad del siglo v a.C. (Fig. 11, no 1). También están representados el Taller de las Pequeñas Estampillas (Fig. 11, $\mathrm{n}^{\mathrm{o}}$ 7) y, sobre todo, las producciones de barniz negro de los talleres occidentales del siglo III a.C., en particular el Taller de Roses (Fig. 11, n ${ }^{\circ} 8$ 12), de modo que sería posible pensar, teóricamente, en una ocupación continuada del asentamiento desde la segunda mitad del siglo IV a.C. hasta su destrucción en torno a 200 a.C. Sin embargo, también es plausible que los materiales más antiguos llegaran con los primeros ocupantes del lugar, a mediados o en el tercer cuarto del siglo III a.C., puesto que la perduración de uso de las cerámicas áticas durante largos períodos de tiempo es un hecho perfectamente comprobado. Teniendo en cuenta la naturaleza de la estratigrafía, esta segunda hipótesis es, a nuestro entender, la más verosímil. Lo contrario implicaría suponer que la estratificación del yacimiento no experimentó crecimiento alguno durante más de un siglo — algo poco probable_-, o bien que el posible asentamiento más antiguo se hallaba solamente en un área limitada, y aún inexplorada, del lugar.

En cuanto a posibles ocupaciones anteriores al período ibérico pleno, tan sólo se ha documentado una urna cineraria atribuible al período I de S. Vilaseca, o Campos de Urnas antiguos de Ruiz Zapatero, localizada in situ debajo del pavimento del recinto 9 del edificio 1. Esta pieza, fechable tipológicamente entre los siglos XI a.C. y IX a.C., debió de formar parte de una necrópolis más amplia, de la que sólo nos han llegado algunos fragmentos, descontextualizados, de otros vasos similares. En el extremo opuesto de la horquilla cronológica, puede asegurarse la existencia de una reocupación entre la segunda mitad del siglo II a.C. y principios de la siguiente centuria, que queda atestiguada, sobre todo, por la relativamente importante cantidad de cerámicas de esta cronología halladas en los niveles superficiales, donde también se han recuperado algunas monedas de época republicana. ${ }^{7}$ Se trata sobre todo de cerámica de barniz negro del círculo de la campaniense $B$, entre la que parece predominar la de producción etrusca, aunque también se documentan vasos de tipo "B-oide". El repertorio de formas es notable e incluye las copas Lamb. 1 y Lamb. 2 (Fig. 13, no 6 y 10), los platos Lamb. 5 y Lamb. 8b (Fig. 13, no 8 y 5), el pyxis Lamb. 3 (Fig. 13, $\mathrm{n}^{\circ}$ 9), el cuenco ápodo Morel 2150 (Fig. 13, n 7 ), el cuenco con asas Pasquinucci 127 y la urna con asas Lamb. 10 (Fig. 13, no 11 y 12).

La campaniense A está representada sobre todo por las páteras Lamb. 5 y Lamb. 6 (Fig. 13, n 1- 2), y tal vez también Lamb. 55 (Fig. 13, n 4), además del pequeño cuenco Morel 113 (Fig. 13, n 3). Debe añadirse a ello la presencia de cerámica de paredes finas, con bordes exclusivamente de la forma Mayet II (Fig. 13, no 13-16), ánfora itálica Dr. 1B (Fig. 13, $\mathrm{n}^{\circ}$ 17) y cerámica de cocina itálica. Los restos de construcciones atribuibles a este período son mínimos, probablemente a causa de la ya descrita actividad antrópica posterior al período ibérico. La natu-

\footnotetext{
${ }^{7}$ (Tarradell-Font 2003-2004: 297-299). Estos materiales condujeron a Ramon Pallarès a proponer, equivocadamente a nuestro entender, una continuidad fluida de la vida del asentamiento hasta finales del siglo II a.C. (Pallarès 1984b: 119).
} 


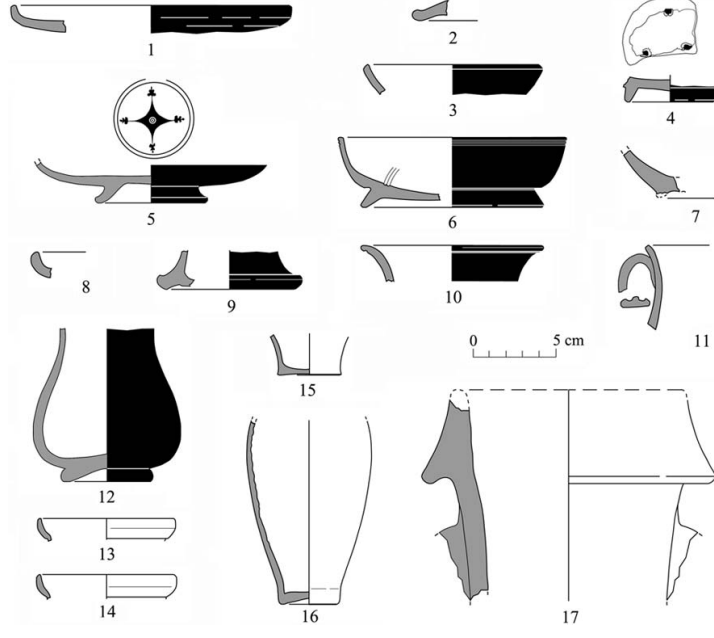

Figura 13. Cerámica importada de los niveles superficiales: 1 a 4 Campaniense A; 5 a 12) Campaniense del círculo de la B; 13 a 16) Cerámica de paredes finas; 17) Ánfora itálica.

raleza de la última ocupación antigua es, por tanto, completamente desconocida. No obstante, y a juzgar por el volumen y dispersión de los materiales que le pueden ser atribuidos — que aparecen en todos los sectores explorados-, debió de ser un asentamiento importante.

\section{EL SISTEMA DEFENSIVO Y SU CRONOLOGÍA}

La muralla del asentamiento ha sido documentada en la zona noroeste, donde, a pesar de su mala conservación, es perfectamente reconocible, y, en mucho mejor estado, a ambos lados de la puerta de acceso al poblado (Figs. 4, 8 y 9). Está formada por dos muros paralelos, que siguen estrechamente el límite de la plataforma y distan el uno del otro unos $3,20 \mathrm{~m}$ en el sector situado junto a la torre norte, unos $2,50 \mathrm{~m}$ en el sector opuesto, y nuevamente unos $3 \mathrm{~m}$ en la zona noroeste. El muro exterior es de un grosor considerable (unos $0,60-0,70 \mathrm{~m}$.) en relación al resto de construcciones $(0,30-0,40 \mathrm{~m})$, aunque en algún punto mide sólo $0,45 \mathrm{~m}$. Una serie de paredes transversales divide este largo espacio en un gran número de compartimentos, de formas y dimensiones desiguales (entre $6,2 \mathrm{~m}^{2}$ y $27,5 \mathrm{~m}^{2}$ en el sector noroeste; entre $10,20 \mathrm{~m}^{2}$ y $41 \mathrm{~m}^{2}$ en el sector septentrional del extremo este).

Ramon Pallarès supuso en su momento que los compartimentos entonces conocidos — los del extremo meridional- contenían un encofrado de tapial, de modo que, según él, se trataría de una muralla maciza. Ahora bien, dejando aparte las dificultades de orden constructivo de esta hipótesis - ya oportunamente señaladas por Pierre Moret (1996: 83-84)—, existen pruebas concluyentes de que se trata de compartimentos vacíos, utilizados para diversas funciones. Así, dos de los tres existentes en el extremo del tramo meridional presentan un enlosado de piedra, y los del lado opuesto, recientemente excavados por nosotros, contienen hogares, uno de los ellos relacionado con actividades de fusión de bronce (recinto 134) (Fig. 9). Un cuarto compartimento de la misma zona, inmediatamente al oeste, forma parte de un complejo más amplio (edificio 19), con indicios claros de trabajo del hierro. En cuanto al sector noroeste, todo lo que puede decirse es que alguno de los compartimentos parece relacionado con las casas adyacentes, en particular el recinto 85, que también conserva restos de un hogar, o el recinto 80 (Fig. 8). Otros, como los recintos 81 y 82 , parecen incomunicados, de modo que no puede excluirse un acceso cenital, desde el paso de ronda.

La existencia en el Castellet de Banyoles de una muralla con compartimentos vacíos en el nivel inferior no tiene nada de particular, puesto que este tipo de fortificación, de origen oriental, está perfectamente documentado en el sur de la península ibérica (Bendala y Blánquez 2002-2003; Bendala 2010) y su influencia se refleja también, probablemente, en otros yacimientos al norte del Ebro, en particular en el sector con casamatas de la muralla del Turó del Montgròs (El Brull, Osona, Barcelona), fechado en torno a 300 a.C. (López y Riera 2005), y en la muralla con recintos cuadrangulares adosados del Casol de Puigcastellet (Folgueroles, Osona, Barcelona), de la segunda mitad del siglo III a.C. (Molas, Rocafiguera y Mestres 1988). Es cierto que el reducido espesor del muro exterior de la muralla del Castellet de Banyoles podría suponer una cierta endeblez para una estructura sin relleno, pero no debe olvidarse que la altitud de la plataforma y el escarpe acusado de las pendientes que la delimitan la hacían difícilmente vulnerable por la acción de arietes o proyectiles. Por la misma razón, probablemente, se prescindió del uso de torres, de las que no existe rastro alguno conocido.

El único punto realmente vulnerable del sistema defensivo era la puerta, aunque el largo y estrecho istmo que la precedía constituía ya de por sí una defensa considerable, dado que permitía obstaculizar el acceso de las máquinas de asedio (Figs. 2 y 7). Las dos torres pentagonales que la protegen constituyen el elemento arquitectónico más emblemático del ya- 
cimiento, pero su conocimiento y, en particular, su datación, están seriamente limitados por la forma en que fueron excavadas, a principios de los años cuarenta, ya que la eliminación, sin un adecuado registro, de toda la sedimentación arqueológica en contacto con las mismas supone la imposibilidad de fecharlas directamente. Más tarde, las intervenciones de Ramon Pallarès, aunque trajeron luz a otros elementos de interés - como la continuación de la cloaca que discurre entre las dos torres-, fueron excesivamente puntuales para proporcionar una comprensión global de este sector. Pese a ello, el debate sobre la cronología, restitución y filiación cultural de las torres, ha sido incesante (Pallarès 1987; Gracia et alii 1991; Moret 1996; Gracia 2000; Moret 2001 y 2008). Nuestra intervención, desarrollada entre 2008 y 2010, tenía por finalidad esencial aclarar su cronología.

Recordemos brevemente que cada una de las torres, que son prácticamente idénticas, se compone de un cuerpo triangular avanzado, seguramente macizo, $\mathrm{y}$, en la parte posterior, de un espacio cuadrangular vacío, accesible a través de una puerta situada al oeste. A este segundo cuerpo se adosa, en el caso de la torre sur, el último compartimento de la muralla y un breve tramo de muro que prolonga la pared septentrional; en la torre norte, otros dos muros ensanchan hacia el oeste el espacio interior del cuerpo cuadrangular. Es importante observar que todas estas estructuras se adosan a las torres propiamente dichas, de manera que les son posteriores; la datación absoluta de alguna de ellas proporcionaría, por tanto, un valioso terminus ante quem para la erección de las torres, o, por lo menos, del cuerpo cuadrangular vacío de las mismas, suponiendo que el elemento triangular macizo de la parte anterior hubiera sido levantado más tarde, independientemente, lo que es posible, pero en modo alguno seguro.

Las dimensiones de la torre norte son de $12 \mathrm{~m} \mathrm{de}$ longitud por 6,40 $\mathrm{m}$ de ancho, medido éste en el lado occidental, y las de la torre meridional de $10,50 \mathrm{~m}$ y $6,50 \mathrm{~m}$ respectivamente. La luz de la puerta que protegen es de 3,20 m en su punto más estrecho, el exterior. Sin embargo, no es nuestro propósito ofrecer una descripción exhaustiva de estas estructuras, ni una interpretación reconstructiva de las mismas.

El debate sobre estas construcciones se ha centrado en su restitución y, más recientemente, y en conexión con ella, en su cronología. Muy resumidamente, Ramon Pallarés supuso que, siguiendo el modelo de las torres pentagonales helenísticas, comportaban un piso superior sobre toda su superficie, y defendió también, con argumentos más bien tenues - y actualmente insostenibles-, que el trazado de la muralla se prolongaba por el este más allá de las torres, formando una defensa avanzada por delante de éstas (Pallarès 1984b: 123-124). Unos años más tarde, Pierre Moret señaló, con razón, que la restitución propuesta por Pallarès era incomprensible desde el punto de vista estrictamente defensivo, dado que el ángulo agudo frontal de las torres, así como el hecho de que sus ejes fueran convergentes delante de la puerta, implicaban la existencia de un importante ángulo muerto frente a ésta, y la consiguiente imposibilidad de protegerla eficazmente. Ello le condujo a pensar que se trataba de construcciones "de prestigio", sin auténtico valor funcional (Moret 1996: 217-218; 2006: 210). Muy recientemente, sin embargo, y a la luz de un pasaje de Filón de Bizancio (A 44 a 52) sobre las torres pentagonales, el mismo autor ha propuesto una nueva restitución que revaloriza el papel defensivo de las torres (Moret 2008). Según esta interpretación, el cuerpo triangular anterior no se elevaría hasta la altura del piso superior, sino que este último se superpondría únicamente al cuerpo cuadrangular. De este modo, se eliminaría el ángulo muerto frente a la puerta, a la vez que la orientación convergente de las torres permitiría concentrar el tiro en un punto crítico desde el punto de vista defensivo, situado a unos cuarenta metros delante de las mismas. La función del cuerpo triangular se reduciría, por tanto, a proteger la parte inferior del cuerpo cuadrangular de las torres de las maniobras de zapa, la acción de los arietes y los tiros de la artillería.

En relación a la cronología, y en ausencia de datos estratigráficos fiables, Pierre Moret ha supuesto, como hipótesis más probable, que las torres fueron erigidas en un momento relativamente tardío de la vida del asentamiento, posterior a su destrucción en torno a 200 a.C. (o, según él, a principio del siglo II a.C.). Sus argumentos son, por una parte, la aparente incoherencia entre la sofisticación de las torres y la escasa entidad del resto del sistema defensivo, ya que supone que no existía una verdadera muralla (Moret 2008: 209-211); por otra parte, la ausencia de signos de destrucción intencional de las torres y el hecho de que no fueran desmanteladas, como cabría esperar si hubieran existido a principios del siglo II a.C., cuando se produjo la destrucción del poblado (Moret 2008: 208). Como veremos, todo ello es sólo aparente. Finalmente, Moret piensa, con precaución, que los muros que amplían hacia el oeste el cuerpo cuadrangular de la torre meridional fueron construidos con ésta y, dado que uno de ellos se superpone a la pared norte del último compartimento de la muralla, entiende que tanto la torre como los mencionados muros de ampliación fueron elevados en un segundo momen- 
to. Este momento lo sitúa en pleno dominio romano, ya que sólo el ejército romano podría haber servido como "vecteur pour transporter à l'autre bout de la Méditerranée les dernières recettes à la mode de l'architecture hellénistique", recogidas o preconizadas en la obra de un autor, Filón de Bizancio, que escribe a finales del siglo III a.C. (Moret 2008: 210). En definitiva, y sin excluir la posibilidad de una fecha anterior, Pierre Moret introduce en el debate la hipótesis de que las torres se elevaron después de la destrucción del asentamiento del ibérico pleno, producida a "principios" del siglo II a.C. — no necesariamente en 195 a.C.; probablemente más tarde y por obra de otros hispani-, y bajo la influencia directa — ¿o la dirección? - del ejército romano. Nótese que la argumentación que subyace a esta segunda hipótesis está absolutamente condicionada por la fecha en que se escribe la obra de Filón, y también por la idea de que el tipo de torre presente en Tivissa únicamente pudo ser concebido por influencia directa de modelos existentes en el Mediterráneo oriental (donde, por cierto, y como señala el autor, no existe ningún ejemplar del tipo documentado en nuestro yacimiento, con cuerpo triangular equilátero) y que sólo el ejército romano pudo supuestamente transmitir (lo que supone negar que los arquitectos militares púnicos o los griegos al servicio de Cartago pudieran haber conocido y transmitido este modelo de torre).

Sobre algunas de estas cuestiones han arrojado luz nuestros trabajos en este sector del yacimiento entre 2008 y 2010. En primer lugar, y además de comprobar que la sedimentación arqueológica relacionada con la torre norte fue totalmente removida en trabajos anteriores, se ha observado que la tierra acumulada sobre el cuerpo triangular no era, como se pensaba (Pallarès 1984b: 121; Moret 2008: 199), un alzado original en tapial, sino que fue depositada en fechas relativamente recientes, y que incluso una parte, todavía por determinar, del zócalo de piedra había sido construido modernamente. En realidad, los excavadores de los años cuarenta ya señalaban en su informe que "parte del espolón de la torre NE. y dos puntos del muro interior de la torre SE. Fueron derribadas por el mismo fin" (esto es, la destrucción de la ciudad) (Vilaseca et alii 1949: 16). Por consiguiente, una gran parte de la estructura visible hasta 2008, cuya imagen ha sido ampliamente divulgada, era resultado de una reconstrucción, realizada después de la campaña de 1943, según hemos podido saber gracias al análisis por parte del Dr. Jaume Noguera de la correspondencia mantenida entre Salvador Vilaseca y Josep Brull, en la que este último describe brevemente los trabajos realizados. Aunque la remoción completa de la parte reconstruida - condición necesaria para evaluar el estado de la torre en el momento de su excavación- está todavía pendiente, parece evidente que las torres fueron efectivamente destruidas y desmanteladas.

En segundo lugar, la excavación al oeste de la misma torre ha traído a luz el extremo oriental de la muralla norte, en una longitud de $25 \mathrm{~m}$, y ha clarificado más allá de toda duda que se trata de una construcción de compartimentos vacíos (recintos 134 a 137) (Fig. 9). Ahora bien, a diferencia del sector opuesto, donde el último compartimento se adosa al ángulo sudoccidental de la torre sur, en el sector excavado por nosotros existe una puerta lateral, cuyo vano, de 3,5 m de anchura media, está formado por el muro oriental del último compartimento (recinto 134) y por una segunda pared, descubierta en los años cuarenta y ya mencionada, que se adosa al ángulo noroccidental torre. ${ }^{8}$ Una hilada de losas calcáreas de grandes dimensiones constituye el umbral de esta puerta, por la que discurre un ramal de la gran cloaca que atraviesa el acceso principal al asentamiento. La puerta recientemente descubierta se corresponde claramente con una poterna situada en el sector meridional, entre los dos últimos compartimentos de la muralla. Estas aberturas laterales tuvieron probablemente por objeto facilitar las salidas de los defensores - que podían concentrarse en el amplio espacio que las antecede- y la ejecución de golpes de mano contra los eventuales asaltantes.

En lo que se refiere a la cronología de este sector, nada puede afirmarse sobre la fecha inicial, más allá de lo que hemos indicado sobre el conjunto del yacimiento. En cualquier caso, es evidente que la muralla funcionó con las torres, aunque debió de ser construida inmediatamente después - no antes- que ellas. Ello se deduce, en primer lugar, del hecho de que el último compartimento del extremo meridional se adose a la torre sur; en segundo lugar, del hecho de que el muro occidental de la puerta lateral descubierta por nosotros se adose a la torre norte. En cuanto a la fecha de destrucción, en el vano de dicha puerta lateral se conservan restos de un nivel de abandono/destrucción análogo en todo punto al que, como hemos dicho, se documenta en el resto del asentamiento, incluyendo los compartimentos adyacentes de la muralla y el edificio 19. Este nivel fue parcialmente excavado en los años cuarenta, de modo que, desafortunadamente, no tiene contacto con el muro

\footnotetext{
${ }^{8}$ La existencia de esta puerta explica que "el enlace con el muro exterior no se ha podido comprobar", según indican los excavadores (Vilaseca et alii 1949: 19).
} 
oriental que delimita la puerta, pero es lógico suponer que originalmente se entregaba al mismo. Ahora bien, dado que dicho muro oriental se entrega a su vez, como hemos dicho, a la torre norte, la fecha obtenida para el nivel en cuestión y sus homólogos de los recintos situados más al oeste constituye un terminus ante quem para la construcción de las torres. Esta fecha puede ser precisada hasta cierto punto gracias al hallazgo de dos bordes de ánfora grecoitálica, ${ }^{9}$ un asa de copa Morel 68 y un borde de plato Lamb. 36, que fecharíamos en el primer tercio del siglo II a.C. (Fig. 12, no 13-16). En definitiva, la conclusión más probable es que el mencionado estrato se formó a principios del siglo II a.C. (probablemente, en nuestra opinión, en 195 a.C.), lo que supondría necesariamente que la torre norte (y, por ende, también su homóloga meridional) fue construida anteriormente, probablemente en la segunda mitad o, mejor, en el último tercio del siglo III a-C.

\section{LA ARQUITECTURA DOMÉSTICA: UN ATISBO SOBRE LA ORGANIZACIÓN SOCIAL}

La excavación del sector noroccidental ha proporcionado también interesantes datos sobre los tipos de casas existentes a finales del siglo III a.C. en el Castellet de Banyoles, de lo que es posible colegir alguna información sobre la organización social de la comunidad que habitó el lugar.

Entre los edificios del bloque constructivo A destacan tres grandes casas contiguas (edificios 1 a 3 ), de estructura compleja y grandes dimensiones. El edificio 3, al oeste, cubre una superficie de $260 \mathrm{~m}^{2}$, por $350 \mathrm{~m}^{2}$ del edificio 2 y $275 \mathrm{~m}^{2}$ del edificio 1 (Figs. 6 y 8). Tienen todos ellos una estructura similar, con un gran patio abierto - de superficie comprendida entre $65 \mathrm{~m}^{2}$ y $150 \mathrm{~m}^{2}$-, que precede a un conjunto de cinco recintos. Uno de éstos (recintos 37, 20-21 y 19), situado siempre a un lado y paralelo al eje longitudinal del edificio, puede identificarse como cocina y centro de la vida doméstica, por la existencia de uno o (en el edificio 2) dos hogares. En los edificios 3 y 2 , y situado entre el patio, el extremo sudoeste de la cocina y el frente de las tres habitaciones restantes, existe un espacio rectangular orientado transversalmente a estas últimas, lo que permite suponer que se trataba de un pórtico, si bien es cierto

\footnotetext{
${ }^{9}$ Una de ellas, de aspecto relativamente avanzado, podría sugerir una datación algo más tardía, pero la cronología de estos elementos morfológicos es todavía incierta y sujeta a discusión (Asensio 2010).
}

que no hay rastro de basas de columna. Su existencia, además, facilitaría en gran medida la iluminación de unos recintos que, de otro modo, quedarían completamente aislados del exterior. Este rasgo arquitectónico confiere a los mencionados edificios un aire de sorprendente familiaridad con las casas griegas tipo pastàs. En cualquier caso, estos cuatro recintos forman un conjunto bien caracterizado y, en particular los tres espacios del fondo, aislado del resto de la casa. En el edificio 2, el mayor, hay también otros tres pequeños espacios de reducidas dimensiones, en evidente relación con el patio. Aunque la existencia de grandes casas complejas está bien documentada en otros asentamientos ibéricos, como Ullastret (Martín et alii 2004) - entre otros (Belarte 2008; Belarte, Bonet y Sala 2009)_, este tipo específico parece exclusivo del Castellet de Banyoles.

La interpretación funcional de los distintos espacios —excepto las cocinas/ámbitos domésticos_ es muy incierta, habida cuenta del reducido número de objetos hallados. De todas formas, la gran superficie ocupada por el recinto 29, en el edificio 2, sugiere que podía tratarse de un espacio de recepción. Este rasgo, unido a las dimensiones particularmente importantes de este edificio, indicaría que sus habitantes ocupaban un lugar especialmente destacado en la jerarquía social. A ello debe añadirse el hallazgo dentro de esta casa, en el recinto 28 - junto al posible espacio de recepción-, de un colgante y un pendiente amorcillado, ambos de oro e idénticos a los recuperados en 1912 (Fig. 10), lo que probablemente indica que también éstos procedían de esta casa, pues todas las piezas parecen formar parte de un mismo conjunto. Los otros signos de prestigio y riqueza descubiertos desde la reanudación de las excavaciones en 1998 proceden asimismo de estas casas. En el edificio 1, concretamente, se hallaron dos denarios, un victoriato y tres imitaciones ibéricas de dracmas ampuritanas (Fig. 10), que pueden también paralelizarse, excepto el victoriato, con las descubiertas en 1912 (Tarradell-Font 2003-2004: 251) ${ }^{10}$. En esta casa no existe el posible pórtico antepuesto a las habitaciones del fondo, pero sí un segundo cuerpo, formado por los recintos R11, R12 y R16, que fue posiblemente construido más tarde, ya que rebasa la alineación en fachada de estas casas e invade la calle 1. Esta apropiación del espacio público puede

\footnotetext{
${ }^{10}$ Aunque, según Bosch Gimpera (1915: 856), los pendientes y las monedas aparecieron juntos en el interior de un vaso, junto con una reja de arado, dos brazaletes, una fíbula, un anillo y un mango de espejo, parece dudoso que se trate realmente de un conjunto cerrado, como ya sospechó hace años Ramon Pallarès (1984a: 209).
} 
entenderse también como un indicador de poder, por cuanto supone la aceptación por la colectividad del uso privado de un espacio común (Belarte 2008: 199).

Los otros edificios adosados a la muralla, inmediatamente al sudeste de los descritos, y separados de ellos por una calleja (R41), son de dimensiones menores, pero también de notable complejidad estructural. El edificio $4\left(180 \mathrm{~m}^{2}\right)$ tiene una estructura muy similar a la del edificio 2, pero sin patio, y el edificio $5\left(100 \mathrm{~m}^{2}\right)$, asimismo sin patio, presenta también el consabido recinto transversal, que sin embargo da paso a solamente dos habitaciones. Aparte de sus menores dimensiones, se diferencian de los anteriores por la existencia de hogares (incluso más de uno) en la mayoría de recintos. Debe destacarse la presencia en el espacio 48 (edificio 5) de un horno circular con el que se relacionan restos abundantes de plomo fundido. Adosado al muro de fachada del edificio 4, existe un segundo horno, semicircular y construido en piedra, sin duda culinario. Parece evidente que estos dos edificios tenían una funcionalidad muy distinta a los antes descritos.

El bloque constructivo C está situado en el extremo occidental del asentamiento. Destacan en el mismo dos grandes edificios de planta rectangular alargada, formados por habitaciones oblongas y largos corredores, de los cuales tan solo el más meridional (edificio 18) ha sido recientemente excavado. Se trata de una estructura que combina características de los distintos tipos existentes en el bloque A. Por un lado, algunos de sus componentes estructurales (un gran patio delantero y una única estancia con hogar) y la aparición de joyas de oro en los niveles de destrucción (dos nuevas piezas, aún en estudio) remiten a las residencias más preeminentes de aquél (edificios 1 a 3). Por el contrario, sus dimensiones generales (unos $140 \mathrm{~m}^{2}$ ), el número de recintos internos y la evidencia de actividades metalúrgicas (horno de forja de hierro de grandes dimensiones en el patio anterior, así como la presencia de dos nódulos de mineral de galena) recuerdan las características de los edificios 4 y 5).

En cuanto al bloque B, está formado por dos baterías de recintos contiguos que se adosan a uno y otro lado de un muro continuo orientado en dirección noroeste-sudeste. El estado de conservación es a menudo muy precario, lo que dificulta a veces la individualización de las distintas unidades constructivas, sobre todo en la parte noroeste, donde, a excepción de los recintos 113 y 114, tan sólo se conservan, en mayor o menor longitud, los arranques de los muros que se adosan a la mencionada pared medianera. En el lado opuesto, por el contrario, se pueden individualizar distintas casas (edificios 8 a 9 y
11 a 15), de dimensiones relativamente modestas (entre $40 \mathrm{~m}^{2}$ y $90 \mathrm{~m}^{2}$ ) y una estructura mucho más simple que en el bloque A. Se trata, en efecto, de unidades constructivas compactas, sin patio y formadas, en general, por cuatro recintos, aunque los edificios 14,12 y 11 sólo tienen dos, o tal vez tres. Su carácter doméstico parece muy probable, aunque no siempre se comprueba la presencia de hogares. Se trataría, en cualquier caso, de casas mucho más modestas que las del bloque constructivo A. En cuanto a los edificios situados al noroeste del muro medianero, es posible que tuvieran una estructura similar, pero no puede excluirse que fueran mayores y de superior complejidad, tal vez del tipo documentado en el bloque constructivo A. Nada sabemos de sus funciones, evidentemente.

\subsection{El EDIFICIO 10 ¿UN SANTUARIO GeNTILICIO?}

En el extremo oriental del bloque constructivo B, al nordeste del gran muro medianero, existe otro edificio complejo de grandes dimensiones (unos 140 $\mathrm{m}^{2}$ de superficie interna) (edificio 10) (Figs. 8 y 14 a 16). La disposición de las estancias que lo conforman y los elementos que aparecen en su interior son muy particulares, y sin paralelos conocidos en las áreas geográficas próximas. Este edificio se articula en torno a un recinto central prácticamente cuadrado (R116), de unos 5,3 m. de lado, con una pequeña recámara en el ángulo oriental (R117) y una especie de antesala alargada en el lado sudoeste (R112). Aunque esta gran sala cuadrada limita con la calle 1, parece que no comunicaba con ella. El cuerpo central está rodeado al sudeste y al sudoeste por un corredor en forma de L (R125 y R122), accesible desde la calle 1 a través de una puerta que es, aparentemente, la única que comunicaba con el exterior. Este corredor queda interrumpido por una pared que lo separa de un pequeño espacio prácticamente cuadrado (R111), y en la que es posible, aunque no seguro, que existiera una puerta. La existencia de otras puertas que, sin embargo, no resultan muy evidentes ${ }^{11}$, parece necesaria también para comunicar este corredor con el cuerpo central del edificio, y también, ya

${ }^{11}$ El problema de la identificación precisa de las puertas radica en la deficiente conservación de los muros, raramente más allá de las dos hiladas iniciales. Por ello, es posible pensar que algunas de estas estructuras sean fundamentos corridos por encima de los cuales se pudieron habilitar accesos. La presencia de losas planas seguidas (a modo de umbral) o piedras grandes en posición vertical (que pueden indicar el arranque del vano) permiten detectar, al menos de manera hipotética, la existencia de las probables puertas aquí mencionadas. 


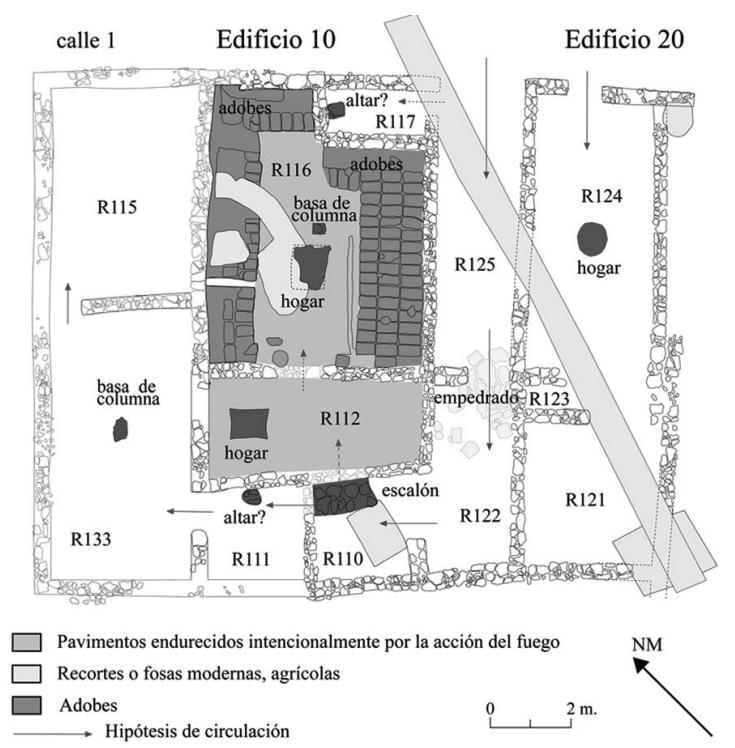

Figura 14. Planta de los edificios 10 y 20.

dentro de este último, la sala central R116 con el vestíbulo que la antecede (R112). También perteneció a este conjunto la construcción rectangular situada inmediatamente al noroeste, formada por dos ámbitos (R115 y R133, con una superficie total de $41 \mathrm{~m}^{2}$ ), y que comunicaba con R111. Por el contrario, el espacio situado inmediatamente al sureste, formado por los recintos 121 y 123-124, corresponde probablemente a una casa del tipo sencillo propio del bloque constructivo B (edificio 20).

Aparte de su posición, el recinto central R116 destaca también por diversas peculiaridades. En primer lugar, por su pavimento, hecho de tierra endurecida intencionalmente con fuego, caso único, por lo conocido hasta ahora, en el yacimiento. Además, este

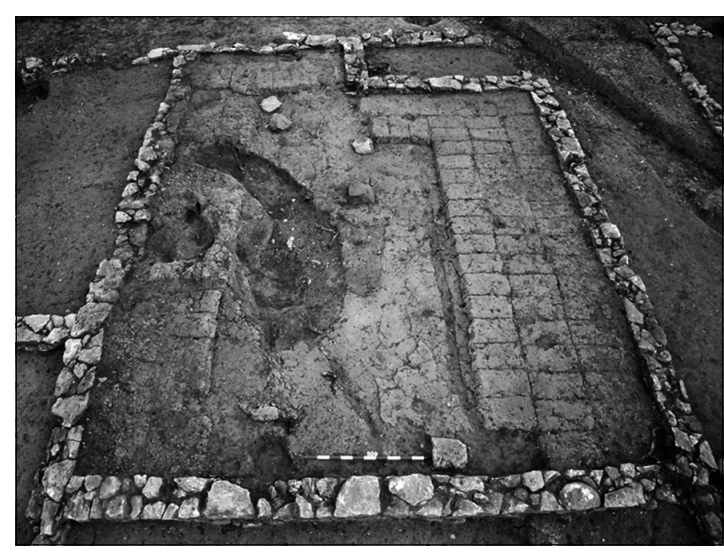

Figura 15. El recinto 116 del edificio 10 desde el sudoeste.

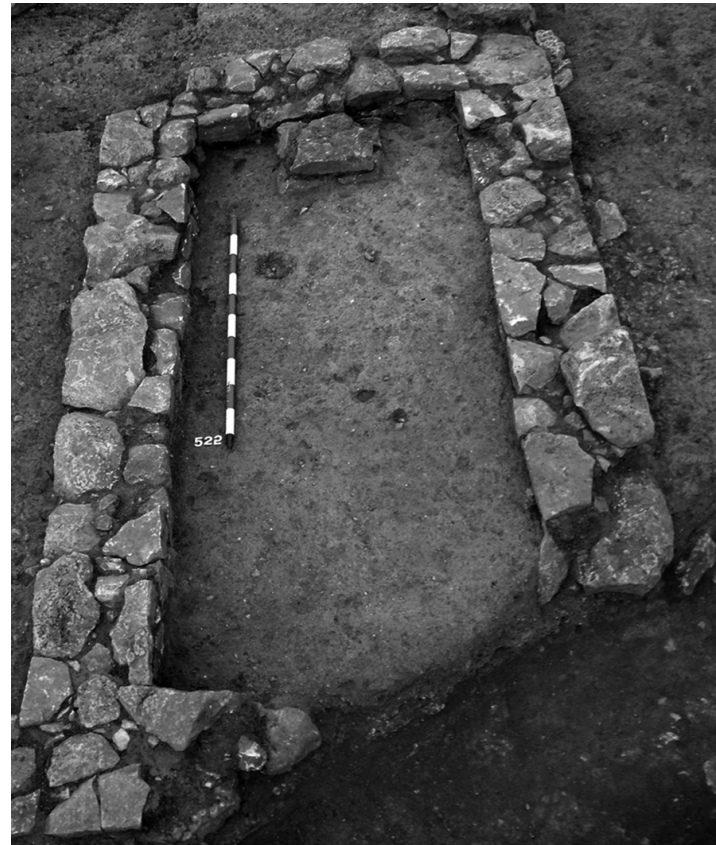

Figura 16. El recinto 117 del edificio 10 desde el este.

pavimento fue cubierto con distintas hiladas de adobes, que formaban una suerte de plataforma de unos $0,20 \mathrm{~m}$ de altura, adosada a las paredes — excepto, parcialmente, en el lado sudoeste-, dejando de este modo en el centro de la habitación, y a un nivel ligeramente inferior, un espacio central rectangular, en el que se conservan los restos, muy deteriorados, de un gran hogar, y también una basa de columna de forma cuadrangular, cuidadosamente labrada (Figs. 14 y 15).

La ausencia de la plataforma de adobes junto al muro sudoccidental sugiere la posible existencia de una puerta. Un pavimento muy similar, también endurecido con fuego, se encuentra en el recinto R112, donde también existe un hogar rectangular, en este caso con ángulos apuntados y una forma general próxima a la de "lingote chipriota". En el interior de la pequeña recámara del ángulo oriental (R117) existía, adosada a la pared noroeste, una piedra de 0,40 por $0,35 \mathrm{~m}$, colocada sobre otras dos y que, por su posición, no puede ser considerada como una basa (Fig. 16). Un elemento del mismo tipo se ha documentado adosado al muro nordeste del recinto R111.

En cuanto a las dos grandes alas situadas al sudeste y al noroeste, tienen en común su carácter bipartito, pero la primera es considerablemente más angosta rasgo propio de una zona de paso- y la segunda tenía una basa de columna en el recinto R133. La ausencia de materiales muebles significativos impide dar más precisiones sobre su funcionalidad. 
Como ya se ha dicho, un problema particular de todo este conjunto es el de la circulación, ya que no ha sido posible reconocer las aberturas que permitían el acceso a las tres cámaras centrales (R112, R116 y R117) y la comunicación entre ellas (Fig. 14). Una hipótesis verosímil es que el recinto central (R116) fuera accesible por el sudoeste, a través de una puerta algo elevada - es decir, con el umbral sobre el basamento-, desde el recinto R112, al que se llegaría, a su vez, desde el recinto R110, también gracias a una puerta elevada, situada cerca del ángulo septentrional; pueden ser un indicio de ello las dos hiladas de grandes piedras situadas junto a este ángulo. Igualmente enigmática es la comunicación con las alas sudeste y noroeste, suponiendo que, como parece probable, formaran efectivamente parte de este edificio. Como se ha dicho, las puertas podían estar ligeramente elevadas, pero no puede excluirse que la circulación se realizara esencialmente al nivel de un piso superior, y que el acceso a los recintos centrales fuese, por tanto, cenital.

No es fácil reconocer las funciones del edificio 10 , ya que apenas se han recuperado materiales abandonados in situ y, como es habitual en el yacimiento, los restos de fauna están muy mal conservados, o simplemente han desaparecido. Además, la excavación se ha interrumpido, de momento, al nivel de los pavimentos y de los hogares, ninguno de los cuales ha sido levantado. En cualquier caso, está claro que su estructura es radicalmente distinta de la de las casas descubiertas en el yacimiento; asimismo, la organización interna de la gran sala cuadrada (recinto 116) es muy peculiar, y no creemos que responda a funciones domésticas. $\mathrm{Si}$, por consiguiente, excluimos que se trate de una casa, debemos suponer que es un edificio comunitario, destinado a funciones administrativas, religiosas o políticas, sin que sea posible optar claramente por una de estas posibilidades, que, por lo demás, tampoco son mutuamente excluyentes. Parece claro que la gran sala cuadrada, con su plataforma de adobes y un hogar central, tiene una estructura apropiada como lugar de congregación y, tal vez, de consumo comunitario de alimentos. En cuanto a los bloques de piedra adosados a las paredes de los recintos 111 y 117, su función no era constructiva, lo que permite pensar que fue ritual; tal vez se tratara de altares. Asimismo, el pequeño espacio R117 recuerda, por sus dimensiones y ubicación, las pequeñas "dependencias sacras" - un rasgo de probable origen oriental- que aparecen frecuentemente en edificios cultuales prerromanos entre el Ebro y la baja Andalucía (Prados 2006). Añádase a ello el hecho de que la gran sala central, que es el núcleo del edificio, no resulta accesible con facilidad desde el exterior, sino que probablemente fuera necesario, para entrar en ella, recorrer todo un corredor en L hasta el recinto 110 , y después pasar por una antesala (recinto 112) cuyo carácter religioso parece probable a tenor de la presencia de un hogar en forma de lingote chipriota. Existe una evidente voluntad de aislamiento, que sería todavía mayor si, como ya hemos sugerido, fuera cierto que muchos de estos recintos sólo eran accesibles cenitalmente.

Esta voluntad de aislamiento conduce a pensar en la celebración de cultos mistéricos y tal vez de rituales iniciáticos como hipótesis de trabajo, aunque, naturalmente, de muy difícil verificación. En este sentido, podría tener una cierta relevancia la posible relación con este edificio de las phiálai mesómphaloi descubiertas en 1927, dos de las cuales tienen en los umbos representaciones de cabezas de lobo, un animal que ha sido relacionado con este tipo de actividades (Almagro-Gorbea 1996: 109). En efecto, aunque desconocemos el lugar preciso en que se produjo el hallazgo de las phiálai, según Ramon Pallarès era próximo al del "tesoro" recuperado en 1912, que ya hemos mencionado (Pallarès 1984a, vol. 1: 219). Ahora bien, ya hemos señalado las razones que permiten pensar que el hallazgo de 1912 se produjo en el solar de nuestro edificio 1, de modo que no es inverosímil suponer que el conjunto de 1927 fue recuperado en el edificio $10 \mathrm{o}$ en su proximidad. ${ }^{12} \mathrm{La}$ relación entre estos vasos y un templo ya había sido propuesta por Vilaseca, Serra-Ràfols y Brull (1949: 46 y 53), y más tarde por Pallarès (1984a, vol. II: 58). Posteriormente, M. Almagro-Gorbea atribuyó estos vasos al culto funerario dedicado a régulos heroizados (Almagro-Gorbea 1996: 113), que bien podría haberse tributado en un edificio como el que hemos descrito. La proximidad del mismo a las grandes residencias aristocráticas del bloque A (edificios 1 a 3 ) también permite apoyar esta interpretación, o, por lo menos, el carácter cultual de la construcción. Finalmente, la comprensión de este edificio debe tener también en cuenta la existencia delante del mismo de un gran espacio abierto que se extiende hasta las fachadas de los edificios 4 y 5 . Este espacio parece concebido para permitir la congregación de un número importante de personas $\mathrm{y}$, por tanto, probablemente para funciones de carácter político y religioso.

12 Podría objetarse que las escasas referencias conocidas sobre los lugares de hallazgo sugieren una situación algo más cercana al límite occidental del poblado, y más próxima a su eje longitudinal. Pero no es necesario recordar aquí la imprecisión de tales noticias orales y de su transmisión. 
No conocemos paralelos claros para esta estructura, pero existen algunos puntos en común con el edificio 203 del asentamiento de Alorda Park (Calafell, Baix Penedès, Tarragona). Se trata de una gran construcción (unos $315 \mathrm{~m}^{2}$ ), datada en el siglo III a.C. y destruida, como el resto del poblado, en una fecha cercana a la del Castellet de Banyoles. Uno de los siete recintos que la componen (AB) tenía bajo el pavimento los restos de sacrificios de ocho ovicápridos, pero es particularmente interesante el recinto $\mathrm{AH}$, un pequeño espacio prácticamente cuadrado, al que se accedía por una puerta situada al fondo de un corredor en L. En un segundo momento, esta puerta fue tapiada, de modo que el acceso al recinto debía de ser cenital. En el nivel de derrumbe se hallaron dos cráneos completos de grandes cánidos, que posiblemente estaban sujetos a las paredes o colocados sobre estantes (Asensio et alii 2005: 604).

\section{BALANCE Y PERSPECTIVAS}

El Castellet de Banyoles es, por distintos motivos, un yacimiento peculiar. Su primera singularidad radica en la cronología inicial. Fundado, en nuestra opinión, hacia el tercer cuarto del siglo III a.C. —o, como mucho, un siglo antes-, se trata del único asentamiento ibérico de grandes dimensiones que no hunde sus raíces en el ibérico antiguo o, incluso, en el primer hierro. Ciertamente, existen en Cataluña otros poblados fundados en fechas igualmente tardías, como Els Estinclells (Verdú, comarca de Urgell, Lérida), cerca de Tàrrega (Asensio et alii 2009), o el Puig Castellet de Lloret de Mar (Pons et alii 1981), pero ninguno posee la entidad del de Tivissa. Ello demuestra que el proceso de crecimiento de la población iniciado en el Bronce Final y potenciado, a partir del siglo vi a.C., con la aplicación de la metalurgia del hierro a las actividades productivas (Sanmartí 2010), proseguía aún durante el siglo III a.C. en algunas zonas que, por razones que desconocemos, parecen haber estado poco pobladas desde mediados del siglo vi a.C., tal vez por tratarse de territorios de frontera. La cubeta de Mora — una zona que cuenta con trabajos de prospección de una cierta importancia - fue, sin duda, una de ellas, tal como muestra la práctica ausencia de yacimientos anteriores al ibérico pleno (Noguera 2002: 19-21).

La fundación ex novo de un núcleo de la entidad y volumen de población del Castellet de Banyoles hubo de suponer la colonización agrícola de la hoya, pero no implicó aparentemente la formación de un poblamiento rural disperso, ya que el número de yacimientos conocidos apenas experimentó crecimiento alguno (Noguera 2002: 30-33). Debemos suponer, por consiguiente, que la población se concentró casi exclusivamente en este gran asentamiento, lo que es perfectamente posible, ya que el poblado se encuentra en una posición central dentro de la cubeta y que, exceptuando su extremo norte, la mayor parte de terrenos cultivables de ésta se halla dentro de un radio de $5 \mathrm{~km}$. Por tanto, eran accesibles en más o menos una hora, excepto los más alejados de la derecha del Ebro, que es el único obstáculo de una cierta importancia para la circulación. El asentamiento aparece de este modo como una pequeña ciudad, en la que coexisten distintos grupos sociales y que concentra las actividades secundarias — sobre todo la metalurgia- y servicios diversos de carácter religioso, defensivo y administrativo.

Es necesario preguntarse por qué razón se optó por este modelo estrictamente mononuclear, o casi, cuando en las regiones costeras existen sistemas de asentamientos profundamente jerarquizados, que incluyen un importante poblamiento disperso, y en otras zonas, como la Cataluña central y occidental o el Bajo Aragón se documenta un modelo aldeano de tipo heterárquico, sin grandes núcleos de población (Sanmartí 2010). La concentración de toda la población en un solo asentamiento no es la fórmula más económica desde el punto de vista de la explotación agrícola del territorio, de modo que su elección debe explicarse por razones de otra índole, y entre ellas debieron de ser primordiales las de carácter estratégico. En efecto, la existencia de un lugar tan eficazmente protegido por la configuración del terreno y, a la vez, suficientemente amplio para albergar a una población considerable, amén de su situación en el centro de la hoya y la proximidad a distintas vías de comunicación, debió de tener un papel importante en esta decisión. La preocupación por la defensa que se deduce de todo ello puede deberse, sobre todo, al estado de confrontación endémico entre los pueblos ibéricos, pero no podemos excluir que la inestabilidad provocada en la península ibérica por la invasión bárquida hubiera pesado también en la toma de decisiones. También es probable que se tuviera en consideración la proximidad de la zona minera del Molar, ya que entre las actividades de transformación documentadas tiene un papel importante la relacionada con el plomo, atestiguada por la presencia de una considerable variedad de objetos (proyectiles, pesos de red, ponderales, un pico en miniatura, un elemento monetiforme), de dos bloques de galena y un elevado número de restos de plomo fundido. ${ }^{13}$ Es posible que esta actividad explique la práctica inexistencia de restos de fauna, ya que los 
huesos calcinados y molidos son un componente idóneo de las copelas (Ferrer 2002: 203).

Una segunda peculiaridad radica, evidentemente, en el sistema defensivo. En primer lugar, por la existencia de una muralla de compartimentos, un tipo de fortificación de origen oriental, frecuente en el mundo fenicio-púnico, también en su área de influencia del sur de la Península Ibérica, pero que constituye una rareza al norte de Alicante, donde su presencia solo se documenta en un pequeño sector del Turó del Montgròs (López y Riera 2005) y hasta cierto punto en el Casal de Puigcastellet (Folgueroles, Osona, Barcelona) (Molas, Rocafiguera y Mestres 1988). El uso sistemático de este tipo de fortificación en la muralla de un asentamiento tan importante de esta región es, creemos, un hecho notable, cuya explicación no es sencilla, pero que revela una familiaridad real con los sistemas púnicos de fortificación, hasta el punto de que podría pensarse que la propia fundación del poblado — que no puede desligarse de la erección de la muralla - se debió a una iniciativa cartaginesa, tal vez, como ha sugerido M. Bendala (2010), en el marco de una estrategia global de preparación de la retaguardia con vistas a la guerra contra Roma. Aparte del ya mencionado Turó del Montgròs, esta idea encontraría quizá un cierto apoyo en la posible existencia de un castrum cartaginés en la parte alta de Tarragona, donde se encuentra actualmente el Palacio Arzobispal (Bendala y Blánquez 2002-2003: 155-157; Bendala 2010: 454-456). A ello podría añadirse todavía la existencia en edificios religiosos — los templos de la acrópolis de Ullastret-y en grandes residencias aristocráticas de núcleos poderosamente fortificados —Ullastret (Martín et alii 2004: 272 y 282-283) y Alorda Park (Asensio et alii 2005: 603) de pavimentos y revestimientos de muros fechables en el siglo III a.C. avanzado que responden a una técnica puramente púnica y que tal vez indiquen la presencia en esos lugares de personas de origen cartaginés. En cuanto a las torres pentagonales, nada podemos añadir a la restitución propuesta por Moret, sin duda la más verosímil de cuantas se han elaborado, pero entendemos que su cronología debe elevarse sin duda al momento de fundación del poblado, tal vez en el tercer cuarto del siglo III a.C. o poco después. Ello excluye una transmisión a través del ejército romano - a menos que se acepte una datación extremadamente baja dentro del arco cronológico plausible para la fundación de la ciudad-e impli-

${ }^{13}$ En total, los restos de plomo (302 elementos) representan el $70 \%$ de los elementos metálicos documentados, cuando no suelen superar el $5 \%$ en los yacimientos ibéricos (Rafel et alii 2008: 262). ca — si no se admite una creación paralela en el ámbito ibérico- alguna forma de relación a través del mundo griego o, tal vez más probablemente, púnico, habida cuenta del modelo de muralla de compartimentos utilizado. ${ }^{14}$ Por lo demás, la conexión del Castellet de Banyoles con el ámbito cultural cartaginés viene también sugerida, como se ha visto, por algunos detalles estructurales del edificio cultual - concretamente la "dependencia sacra" R-117-, por el hallazgo de un recipiente fabricado posiblemente con plata de Cartagena (Rafel et alii 2008: 265) e incluso por la presencia entre los materiales más antiguos de dos platos áticos con borde engrosado forma Morel 2220 (Plate with rolled rim del ágora de Atenas), una forma extremadamente rara en los asentamientos ibéricos, pero frecuente, precisamente, en Cartago (Morel 1991: 328-330) (Fig. 11, no 2 y 3). En sentido contrario, sin embargo, es preciso destacar que el Castellet de Banyoles apenas ha proporcionado importaciones de origen púnico, en neto contraste con lo habitual en los yacimientos contemporáneos de la zona. De hecho las importaciones cerámicas presentan índices considerablemente bajos (un $2 \%$ del total de fragmentos o un $7 \%$ en el recuento por individuos) y entre éstas el predominio absoluto es de los productos itálicos, tanto en ánforas como en vajilla (el $91 \%$ del total de fragmentos de importación). Este último dato podría reflejar unas circunstancias particulares del momento inmediatamente anterior a la destrucción de la ciudad, determinadas por la probable presencia de un campamento militar romano en sus inmediaciones (Noguera 2008).

Desde el punto de vista social, es evidente la presencia en el poblado de la aristocracia ibérica, revelada tanto por la arquitectura doméstica como por el hallazgo de objetos suntuarios de carácter ritual que - tercera peculiaridad- constituyen también un caso único en el entorno geográfico próximo, incluyendo otros núcleos de primer orden destruidos violentamente, como Ullastret. La existencia de otras casas de dimensiones más reducidas muestra, sin embargo, que en el poblado residían también los miembros de otros linajes de rango inferior, probablemente vinculados por lazos de clientela con las grandes familias que ocupaban las casas 1-3 del sector noroeste. Se trata de una forma de organización esencial-

${ }^{14}$ Pierre Moret (2008: 205) señala con toda razón que: "l'ensemble architectural des défenses de la porte du Castellet de Banyoles s'avère fondé sur un projet très précis, cohérent et remarquablement adapté aux particularités du lieu”, y precisa que “on est là, sans nul doute, face à l'oeuvre d'un architecte militaire compétent", que bien pudo ser un cartaginés o tal vez un oscuro oficial griego - como el propio Filón de Bizancio (Moret 2009: 210)— al servicio de Cartago. 
mente análoga a la definida por A. Ruiz para la Plaza de Armas de Puente Tablas, en el territorio por excelencia con formas de organización mononuclear (Ruiz 1998: 292). Podemos suponer que el sector traído a luz en el extremo noroeste del Castellet de Banyoles es parte del espacio correspondiente a un grupo gentilicio concreto, con sus casas de distintos tipos y su santuario, y que este esquema debe de repetirse en otras partes del asentamiento, sin excluir que pueda existir también un edificio de tipo palacial, residencia del jefe supremo. Todo ello, en la medida de lo posible, será objeto de investigación en los próximos años.

Indiquemos, para terminar, que, si bien es imposible afirmarlo con toda certeza, creemos que la fecha de 195 a.C. sigue siendo a nuestro entender la más verosímil para la destrucción del Castellet de Banyoles. No se trata de un caso aislado: otros muchos centros de poder -como Ullastret-, asentamientos con valor estratégico y lugares de acumulación de excedentes en el territorio de la actual Cataluña encuentran su final - a veces claramente violentoen las mismas o cercanas fechas. Si bien es cierto, como supone Pierre Moret, que los materiales cerámicos hallados en estos niveles de destrucción y/o abandono podrían fecharse hasta, más o menos, 170 a.C., quizá en algún caso algo más tarde, no nos parece lógico suponer que el poder romano tolerara un período de inestabilidad tan prolongado, de un cuarto de siglo o incluso más, después de la campaña de Catón. Sea como fuere, en el caso del Castellet de Banyoles la ausencia de monedas posteriores a los primeros años del siglo ir a.C. en los niveles de destrucción sugiere que no pervivió más allá de esta última fecha. La fecha de 195 a.C. parece, pues, la más apropiada, no sólo para el Castellet de Banyoles, sino para la mayoría de yacimientos que presentan la facies antigua de la campaniense A en sus niveles de abandono. La campaña de Catón, por tanto, no aparece como una mera expedición punitiva y de pacificación del territorio, sino como una verdadera guerra de conquista, que subvirtió radicalmente las formas de organización política y social del mundo indígena y sometió a la población local a un nuevo orden de dependencias, no necesariamente más opresivas que las existentes bajo el dominio de las aristocracias ibéricas. Sobre ello, sin embargo, se hablará más extensamente en un próximo trabajo ${ }^{15}$.

\footnotetext{
${ }^{15}$ Los autores desean expresar su agradecimiento a los revisores anónimos de este texto, cuyos comentarios, aportaciones y rectificaciones han enriquecido notablemente el contenido del mismo. También a Pierre Moret, por sus precisiones y comentarios, siempre sugerentes.
}

\section{BIBLIOGRAFIA}

Adroher, A. M. 1998: "Materiales de los siglos III y II a.n.e. en Lattes (Hérault, Francia)", J. Ramon, J. Sanmartí, D. Asensio y J. Principal (eds.), Les fàcies ceràmiques d'importació a la costa ibérica, les Balears i les Pitiüses durant el segle III a.C. i la primera meitat del segle II a.C, Arqueo Mediterrània 4, 217-241.

Almagro-Gorbea, M. 1996: "Lobo y ritos de iniciación en Iberia”, R. Olmos Romera y J. A. Santos Velasco (eds.), Coloquio Internacional: Iconografía Ibérica, Iconografía Itálica. Propuestas de Interpretación y Lectura, Serie Varia 3, Madrid, 103127.

Asensio, D. 2010: "El comercio de ánforas itálicas en la Península Ibérica entre los siglos IV y I a.C. y la problemática en torno a las modalidades de producción y distribución", International Congress of Classical Archaeology Roma 2008, Bolletino di Archeologia on line, volume speciale B/ $\mathrm{B} 8 / 3$.

Asensio, D., Belarte, M. C., Ferrer, C., Noguera, J., Sanmartí, J. y Santacana, J. 1994-1996a: "El poblament de les comarques del curs inferior de l'Ebre durant el Bronze Final i la Primera Edat del Ferro", Models d'ocupació, transformació i explotació del territori entre el 1600 i el 500 A.N.E. a la Catalunya meridional $i$ zones limítrofes de la depressió de l'Ebre, Gala 3-5, 301-317.

Asensio, D., Belarte, M. C., Ferrer, C., Noguera, J., Sanmartí, J. y Santacana, J. 1994-1996b: "El jaciment del Barranc de Sant Antoni (Ginestar, Ribera d'Ebre)", Models d'ocupació, transformació $i$ explotació del territori entre el 1600 i el 500 A.N.E. a la Catalunya meridional $i$ zones $l i-$ mítrofes de la depressió de l'Ebre, Gala 3-5, 231246.

Asensio, D., Cardona, R., Ferrer, C., García-Dalmau, C., Morer, J., Pou, J. y Saula, O. 2009: "L'arquitectura domèstica en el nucli fortificat ilergeta dels Estinclells (Verdú, l’Urgell), segle III a.C.", M. C. Belarte (ed.), L'espai domèstic $i$ l'organització de la societat a la protohistòria de la Mediterrània occidental (Ier mil-lenni). Actes de la IV Reunió Internacional d'Arqueologia de Calafell, Arqueo Mediterrània 11, 125-142.

Asensio, D., Cela, X. y Ferrer, C. 1996: "Els materials ceràmics del poblat ibèric del Castellet de Banyoles (Tivissa). Col·lecció Salvador Vilaseca de Reus", Pyrenae 27, 163-191.

Asensio, D., Miró, M. T., Sanmartí, J. y Velaza, J. 2003: "Inscripción ibérica sobre plomo procedente 
del Castellet de Banyoles (Tivissa)", Palaeohispánica 3, 195-204.

Asensio, D., Miró, M. T. y Sanmartí, J. 2002: "El nucli ibèric del Castellet de Banyoles (Tivissa, Ribera d'Ebre): un estat de la questió", I Jornades d'Arqueologia. Ibers a l'Ebre, recerca $i$ interpretació, Ilercavònia 3, Móra d'Ebre, 185-204.

Asensio, D., Miró, M. T. y Sanmartí, J. 2005: "Darreres intervencions arqueològiques en el Castellet de Banyoles (Tivissa, Ribera d'Ebre): una ciutat ibèrica en el segle III a.C.", Món Ibèric als Països Catalans, XIII Col-loqui Internacional d'Arqueologia de Puigcerdà, Puigcerdà 2, 615628.

Asensio, D., Morer, J., Pou, J., Sanmartí, J. y Santacana, J. 2005: "Evidències arqueològiques del procés d'emergència d'élites aristocràtiques a la ciutadell ibérica d'Alorda Park (Calafell, Baix Penedès)", Món Ibèric als Països Catalans, XIII Col-loqui Internacional d'Arqueologia de Puigcerdà, Puigcerdà 2, 597-613.

Belarte, M. ${ }^{a}$ C. 2008: "Domestic architecture and social differences in North-Eastern Iberia during the Iron Age (c. 525-200 BC)", Oxford Journal of Archaeology 27 (2), 175-199.

Belarte, M. ${ }^{a}$ C., Bonet, H. y Sala, F. 2009: "L'espai domèstic i l'organització de la societat ibérica: els territoris de la franja mediterrània", $\mathrm{M}^{\mathrm{a}}$. C. Belarte (ed.), L'espai domèstic i l'organització de la societat a la protohistòria de la Mediterrània occidental (Ier mil-lenni a.C.). Actes de la IV Reunió Internacional d'Arqueologia de Calafell, Arqueo Mediterrània 11, 93-123.

Bendala, M. 2010: "La retaguardia hispana de Aníbal", E. Ferrer (ed.), Los púnicos de Iberia: proyectos, revisiones, síntesis, Actas del VI Coloquio del Centro de Estudios Fenicios y Púnicos, Mainake 32, 1, 437-460.

Bendala, M. y Blánquez, J. 2002-2003: "Arquitectura militar púnico-helenística en Hispania”, Cuadernos de Prehistoria y Arqueología de la Universidad Autónoma de Madrid 28-29, 145-160.

Blázquez, J. M. 1955-1956: "La interpretación de la pátera de Tivissa", Ampurias 17-18, 111-139.

Blázquez, J. M. 1957-1958: "Nuevas aportaciones a la interpretación de la pátera de Tivissa", Аmpurias 19-20, 241-244.

Bosch Gimpera, P. 1915: “Troballes a Tivissa”, Anиari de l'Institut d'Estudis Catalans 1913-14, 856858.

Fernández Fuster, L. 1955: "La phiale ibérica de Tivissa. Ensayo de interpretación", Revista de Archivos, Bibliotecas y Museos 61, 1, 269-282.
Ferrer, M.A. 2002: "Actividad extractiva y metalúrgica”, H. Bonet y C. Mata (coord.), El Puntal dels Llops. Un fortín edetano, Serie de Trabajos Varios 99, Valencia, 192-206.

Garcia y Bellido, A. 1950: "Phiale ibérica de plata con representaciones de asunto religioso de Tivissa (Tarragona)", Homenaje a Luís de Hoyos Sainz II, Madrid, 148-156.

Gracia, F. 2000: "Análisis táctico de las fortificaciones ibéricas", Gladius 20, 131-170.

Gracia, F., Munilla, G. y Pallarès, R. 1991: "Estructuración del poblamiento y sistemas defensivos en el área de la desembocadura del Ebro. Dos casos de estudio: La Moleta del Remei (Alcanar) y El Castellet de Banyoles (Tivissa)", Simposi Internacional d'Arqueologia Ibèrica: Les fortificacions, Manresa, 67-78.

López, A. y Riera, M. 2005: "Resultats de les excavacions de 1997 a 2003 a l'oppidum del Turó del Montgròs, El Brull (Osona)", Món ibèric als Països catalans, XIII Col.loqui internacional d'arqueologia de Puigcerdà, Puigcerdà, 1, 141162.

Marín, M. C. 1983: "Una nueva interpretación de la pátera de Tivissa”, XVI Congreso Nacional de Arqueología, Zaragoza, 709-715.

Martín, M. A., Casas, S., Codina, F., Margall, J. y de Prado, G. 2004: "La zona 14 de l'oppidum del Puig de Sant Andreu d'Ullastret. Un conjunt arquitectònic dels segles IV i III a.C.", Cypsela 15, 265-284.

Molas, M. D., Rocafiguera, M. de y Mestres, I. 1988: "La fortalesa ibèrica del Casol de Puigcastellet (1): una aproximació als límits del territori ausetà", Ausa 121, 97-131.

Morel, J. P. 1991: "La céramique attique à vernirs noir en Ibérie et à Carthage: une comparaison", $\mathrm{P}$. Cabrera, R. Olmos y E. Sanmartí (eds.), Íberos y griegos. Lecturas desde la diversidad, Huelva Arqueológica 13 (2), 323-344.

Moret, P. 1996: Les fortifications ibériques. De la fin de l'âge du Bronze à la conquête romaine, Collection de la Casa de Velázquez 56, Madrid.

Moret, P. 1998: "Rostros de piedra. Sobre la racionalidad del proyecto arquitectónico de las fortificaciones urbanas ibéricas", C. Aranegui (coord.), Actas del Congreso Internacional Los iberos. Príncipes de Occidente. Estructuras de poder en la sociedad ibérica, Barcelona, 83-92.

Moret, P. 2001: "Del buen uso de las murallas ibéricas", Gladius 21, 137-144.

Moret, P. 2006: "Architecture indigène et modèles hellénistiques: les ambiguïtés du cas Ibérique", P. 
François, P. Moret y S. Péré-Noguès (eds.), L'hellénisation en Méditerranée occidentale au temps des guerres puniques (260 - 180 av. J.-C.), Actes du colloque international de Toulouse, $\mathrm{Pa}$ llas 70, 207-227.

Moret, P. 2008: “À propos du Castellet de Banyoles et de Philon de Byzance: une nécessaire palinodie", Salduie 8, 193-215.

Noguera, J. 2002: Ibers a l'Ebre, X Premi d'Assaig Artur Bladé Desumvila 2001, Col.lecció Daliner 3, Centre d'Estudis de la Ribera d'Ebre, Móra d'Ebre.

Noguera, J. 2008: "Los inicios de la conquista romana de Iberia: los campamentos de campaña del curso inferior del río Ebro", Archivo Español de Arqueología 81, 31-48.

Olmos, R. 1996: "Las incertitudes de los lenguajes iconográficos: las páteras de plata Ibéricas”, R. Olmos Romera y J.A. Santos Velasco (eds.), Coloquio Internacional: Iconografía Ibérica, Iconografía Itálica. Propuestas de Interpretación y Lectura, Serie Varia 3, 91-102.

Pallarès, R. 1984a: El poblamiento ibérico de las comarcas de Tarragona (El Castellet de Banyoles, Tivissa, Ribera d'Ebre), tesis doctoral inédita, Barcelona.

Pallarès, R. 1984b: "El sistema defensivo frontal del Castellet de Banyoles, Tivissa, Ribera d'Ebre", Pyrenae 19-20, 113-125.

Pallarès, R. 1987: "Dos elements de filiació grega del segle IV a.C. a l'assentament ibèric del Castellet de Banyoles, Tivissa, Ribera d'Ebre", Protohistòria Catalana, 6è Col.loqui Internacional d'Arqueologia de Puigcerdà, Puigcerdà, 281-288.

Pons, E., Toledo, A. y Llorens, J. M. 1981: El recinte fortificat ibèric de Puig-Castellet-Lloret de Mar (Excavacions 1975-1980), Serie Monogràfica 3, Gerona.

Prados, F. 2006: "Sobre arquitectura ibérica y dependencias sacras: un módulo tipificado a debate", Lucentum 25, 47-69.

Rafel, N., Armada, X. L., Belarte, M. C., Fairén, S., Gasull, P., Graells, R., Morell, N., Pérez, A. y
Villalba, P. 2008: "El área minero-metalúrgica del Baix Priorat (Tarragona) en la Protohistoria. Explotación y redes de intercambio", Revista d'Arqueologia de Ponent 18, 245-269.

Ruiz, A. 1998: "Los príncipes iberos: procesos económicos y sociales", C. Aranegui (coord.), Actas del Congreso Internacional Los iberos. Príncipes de Occidente. Estructuras de poder en la sociedad ibérica, Barcelona, 289-300.

Sanmartí, J. 2010: "Demografía y cambio socio-cultural: el caso de la Iberia septentrional", F. Buri1 lo (ed.), Arqueología de la Población, VI Coloquio Internacional de Arqueología Espacial, Arqueología Espacial, 28, 91-108.

Sanmartí, J., Belarte, M. C., Santacana, J., Asensio, D. y Noguera, J. 2000: L'assentament del bronze final i la primera edat del ferro del Barranc de Gàfols (Ginestar, Ribera d'Ebre), Arqueo Mediterrània, 5, Barcelona.

Sanmartí-Grego, E. y Principal, J. 1998: "Cronología y evolución tipológica de la Campaniense A del siglo II a.C: las evidencias de los pecios y de algunos yacimientos históricamente bien fechados", J. Ramon, J. Sanmartí, D. Asensio y J. Principal (ed.), Les fàcies ceràmiques d'importació a la costa ibérica, les Balears i les Pitiüses durant el segle III a.C. i la primera meitat del segle II a.C, Arqueo Mediterrània, 4, 193-215.

Serra-Ràfols, J. de C. 1941: "El poblado ibérico del Castellet de Banyoles (Tivissa, Bajo Ebro)", Ampurias 3, 15-34.

Serra-Ràfols, J. de C. 1965: "La destrucción del poblado ibérico del Castellet de Banyoles de Tivissa (Bajo Ebro)", Ampurias 26-27, 105-117.

Tarradell-Font, N. 2003-2004: "Les troballes numismàtiques del Castellet de Banyoles de Tivissa (Baix Ebre, Catalunya). Noves troballes de les excavacions 1998-1999 i revisió de les anteriors", Fonaments 10-11, 245-317.

Vilaseca, S., Serra-Ràfols, J. de C. y Brull, L. 1949: Excavaciones del Plan Nacional en el Castellet de Bañolas, de Tivisa (Tarragona), Informes y Memorias 20, Madrid. 